\title{
The Effect of Sodium Selenate Biofortification on Plant Yield, Mineral Content, and Antioxidant Capacity of Culinary Herb Microgreens
}

\author{
Rachel G. Newman \\ West Virginia University, rgnewman@mix.wvu.edu
}

Follow this and additional works at: https://researchrepository.wvu.edu/etd

Part of the Food Science Commons, and the Nutrition Commons

\author{
Recommended Citation \\ Newman, Rachel G., "The Effect of Sodium Selenate Biofortification on Plant Yield, Mineral Content, and \\ Antioxidant Capacity of Culinary Herb Microgreens" (2019). Graduate Theses, Dissertations, and Problem \\ Reports. 3870. \\ https://researchrepository.wvu.edu/etd/3870
}

This Thesis is protected by copyright and/or related rights. It has been brought to you by the The Research Repository @ WVU with permission from the rights-holder(s). You are free to use this Thesis in any way that is permitted by the copyright and related rights legislation that applies to your use. For other uses you must obtain permission from the rights-holder(s) directly, unless additional rights are indicated by a Creative Commons license in the record and/ or on the work itself. This Thesis has been accepted for inclusion in WVU Graduate Theses, Dissertations, and Problem Reports collection by an authorized administrator of The Research Repository @ WVU. For more information, please contact researchrepository@mail.wvu.edu. 
The Effect of Sodium Selenate Biofortification on Plant Yield, Mineral Content, and Antioxidant Capacity of Culinary Herb Microgreens

\author{
Rachel G. Newman
}

Thesis submitted

to the Davis College of Agriculture, Natural Resources, and Design at West Virginia University

\begin{abstract}
in partial fulfillment of the requirements for the degree of
Master of Science in

Nutritional and Food Science
\end{abstract}

\author{
Janet Tou, Ph.D., Chair \\ Nicole Waterland, Ph.D. Co-Chair \\ Youyoun Moon, Ph.D. \\ Department of Animal \& Nutritional Sciences
}

Morgantown, West Virginia

2019

Keywords: selenium, antioxidants, minerals, herbs, microgreens, nutrition

Copyright 2019 Rachel G. Newman 


\section{ABSTRACT \\ The Effect of Sodium Selenate Biofortification on Plant Yield, Mineral Content, and Antioxidant Capacity of Culinary Herb Microgreens}

Rachel G. Newman

Selenium (Se) biofortification of plants has been suggested as a method for enhancing dietary Se intake. Popular herbs such as basil (Ocimum basilicum), cilantro (Coriandrum sativum), and scallions (Allium fistulosum) are used for enhancing flavors. Microgreens are young seedlings harvested with one to two true leaves and are increasingly popular in the consumer marketplace. In this study, basil, cilantro, and scallion microgreens were treated with various concentrations of Se as sodium selenate in hydroponic conditions to investigate the effect on plant yield, mineral content (selenium, sulfur, sodium, potassium, phosphorus, calcium, magnesium, copper, iron, manganese, zinc, and boron), total phenolic compounds, and antioxidant capacity. Results showed scallions had the largest increase in Se content by 98, 202, and 507 times $(p<0.05)$ in $2.5,5.0$, and $10.0 \mathrm{mg} \cdot \mathrm{L}^{-1}$ Se treatments, respectively. At $10.0 \mathrm{mg} \cdot \mathrm{L}^{-1} \mathrm{Se}$, scallions demonstrated increases in all minerals analyzed, total phenolic compounds $(113.7 \%)$, and total antioxidant capacity $(152.2 \%)$, but yield decreased by $68.0 \%$. At the highest Se treatment for basil and cilantro, $5.0 \mathrm{mg} \cdot \mathrm{L}^{-1}$, basil increased in potassium, phosphorus, sulfur, total phenolic compounds (102.6\%), and antioxidant capacity (68.6\%) but decreased plant yield by $35.5 \%$. Cilantro demonstrated increased sodium, total phenolic compounds (50.3\%), and antioxidant capacity $(66.0 \%)$ without an effect on plant yield. Overall, results showed Se biofortification enhances the content of Se, other minerals relevant to human health, and antioxidants in culinary herb microgreens. Nutritionally, scallions at $10.0 \mathrm{mg} \cdot \mathrm{L}^{-1} \mathrm{Se}$ can offer the highest source of Se with added benefits of increases in other minerals and antioxidants. 


\section{ACKNOWLEDGEMENTS}

I would like to first thank Dr. Tou for her constant encouragement, helpful guidance, and friendly reminders to relax. I can’t possibly put all my gratitude into words, but I thank you for supporting me in a task that I thought impossible, all the way to the end. I would like to thank Dr. Waterland and Dr. Moon for introducing me to and allowing me to explore the plant world. Your support, patience, and kindness continue to encourage me. My sincere thanks to Annette Freshour and all of my internship preceptors for their support in the balance of thesis completion and internship responsibilities. I would also like to thank Carl Sams from The University of Tennessee who so generously volunteered his expertise, time, and equipment to the project. I further express my gratitude to Sarah Mills, Derek Warren, and Chris Skinner who helped me with several laboratory and greenhouse tasks throughout the project. Finally, I would like to thank my family for their love and support, and Jamal Palmer for his hundreds of pep talks. 


\section{TABLE OF CONTENTS}

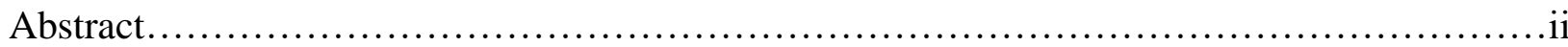

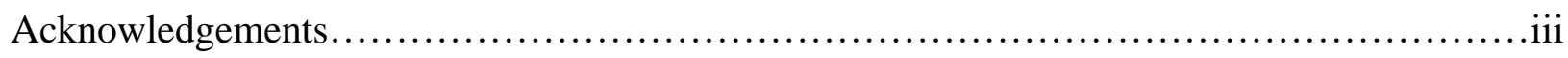

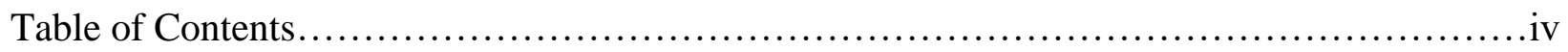

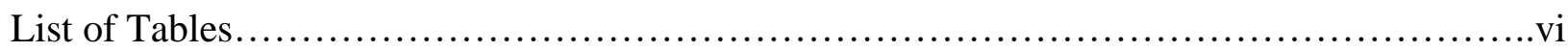

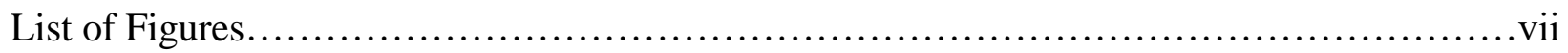

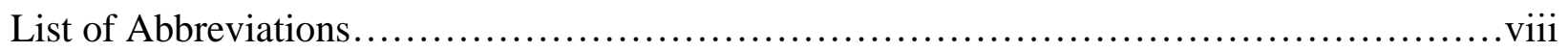

1.0. Literature Review: Selenium Biofortification of Agricultural Crops and Effects on Plant

Nutrients and Bioactive Compounds Important for Human Health and Disease

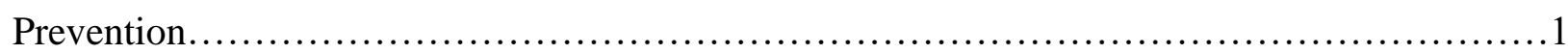

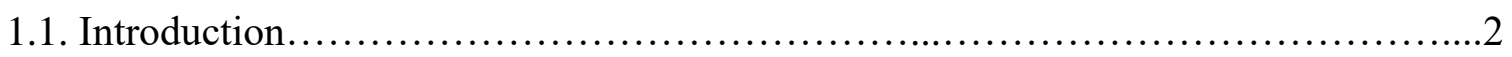

1.2. Role of Selenium in Health and Disease Prevention................................

1.3. Effects of Biofortification on Plant Selenium Content..........................6

1.4. Effects of Biofortification on Minerals Relevant to Human Health...................

1.5. Effects of Biofortification on Antioxidants Relevant to Human Health...............12

1.6. Consumption of Selenium-Biofortified Plants on Human Health....................18

1.7. Conclusions .......................................................20

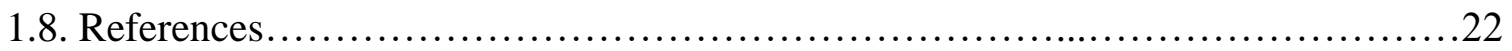

2.0. Chapter 1: The Effect of Sodium Selenate Biofortification on Plant Yield, Mineral Content, and Antioxidant Capacity of Culinary Herb Microgreens.................................... 33

2.1. Introduction......................................................... 34

2.2. Materials and Methods .................................................. 35

2.2.1. Plant Growth and Harvest............................................. 35 
2.2.2. Mineral Analysis.

2.2.3. Determination of Total Phenolic Content...............................37

2.2.4. Oxygen Radical Absorbance Capacity (ORAC) Assay......................38

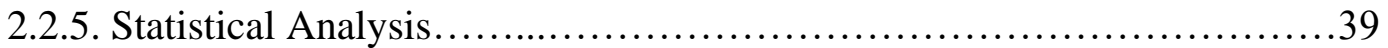

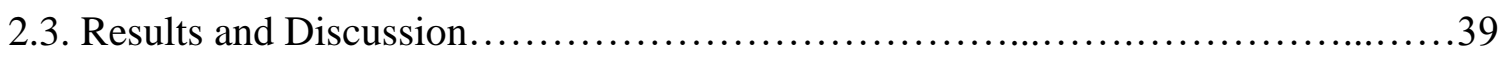

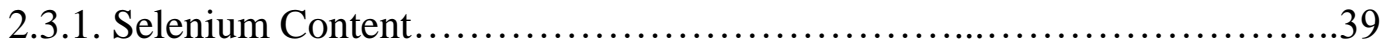

2.3.2. Plant Yield .....................................................41

2.3.3. Other Dietary Minerals........................................42

2.3.4. Total Phenolic Content.............................................45

2.3.5. Total Antioxidant Capacity.......................................46

2.4. Conclusions............................................................ 47

2.5. References.......................................................49

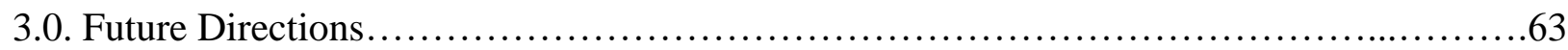




\section{LIST OF TABLES}

Literature Review: Selenium Biofortification of Agricultural Crops and Effects on Plant Nutrients and Bioactive Compounds Important for Human Health and Disease Prevention

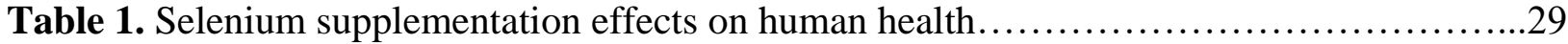

Table 2. Effects of different methods of selenium biofortification on the mineral content in

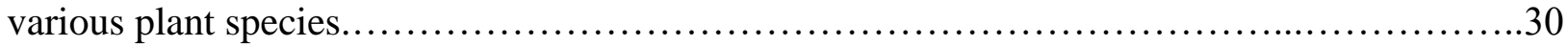

Table 3. Effects of different methods of selenium biofortification on antioxidant compound content in various plant species.

Chapter 1: The Effect of Sodium Selenate Biofortification on Plant Yield, Mineral Content and Antioxidant Capacity of Culinary Herb Microgreens

Table 1. Major mineral content of scallion, basil, and cilantro microgreens treated with different concentrations of Se as sodium selenate, on a fresh weight basis...........................56 Table 2. Trace mineral content of scallion, basil, and cilantro microgreens treated with different concentrations of Se as sodium selenate, on a fresh weight basis 


\section{LIST OF FIGURES}

Chapter 1: The Effect of Sodium Selenate Biofortification on Plant Yield, Mineral Content, and Antioxidant Capacity of Culinary Herb Microgreens

Figure 1. Se content of scallion, basil, and cilantro microgreens treated with different concentrations of Se as sodium selenate, on a fresh weight (A.) and dry weight (B.)

basis. .58

Figure 2. Fresh weight yield of scallion (A.), basil (B.), and cilantro (C.) microgreens treated with different concentrations of Se as sodium selenate.

Figure 3. S content of scallion, basil, and cilantro microgreens treated with different concentrations of Se as sodium selenate, on a fresh weight basis.

Figure 4. Total phenolic content of scallion, basil, and cilantro microgreens treated with different concentrations of Se as sodium selenate, on a fresh weight basis.

Figure 5. Hydrophilic (A.), lipophilic (B.), and total (C.) ORAC values for scallion, basil, and cilantro microgreens treated with different concentrations of Se as sodium selenate, on a fresh weight basis 


\section{LIST OF ABBREVIATIONS}

\begin{tabular}{|c|c|}
\hline $\mathrm{Se}$ & Selenium \\
\hline RDA & Recommended dietary allowance \\
\hline UL & Tolerable upper intake level \\
\hline DW & Dry weight \\
\hline FW & Fresh weight \\
\hline CVD & Cardiovascular disease \\
\hline $\mathrm{RCT}$ & Randomized control trials \\
\hline $\mathrm{RR}$ & Relative risk \\
\hline $\mathrm{CI}$ & Confidence interval \\
\hline SELECT & Selenium and Vitamin E Cancer Prevention Trial \\
\hline HR & Hazard ratio \\
\hline NPCT & Nutritional Prevention of Cancer Trial \\
\hline $\mathrm{Fe}$ & Iron \\
\hline $\mathrm{Cu}$ & Copper \\
\hline $\mathrm{Zn}$ & Zinc \\
\hline $\mathrm{Mn}$ & Manganese \\
\hline PREADViSE & Prevention of Alzheimer's Disease by Vitamin E and Selenium Trial \\
\hline OR & Odds ratio \\
\hline GSH-Px & Glutathione peroxidase \\
\hline CRP & C-reactive protein \\
\hline$S$ & Sulfur \\
\hline $\mathrm{Ca}$ & Calcium \\
\hline $\mathrm{Mg}$ & Magnesium \\
\hline $\mathrm{K}$ & Potassium \\
\hline $\mathrm{Na}$ & Sodium \\
\hline $\mathrm{P}$ & Phosphorus \\
\hline $\mathrm{B}$ & Boron \\
\hline
\end{tabular}




$\begin{array}{ll}\mathrm{Na}_{2} \mathrm{SeO}_{4} & \text { Sodium selenate } \\ \mathrm{SD} & \text { Standard deviation } \\ \mathrm{HNO}_{3} & \text { Nitric acid } \\ \mathrm{HCl} & \text { Hydrochloric acid } \\ \text { ICP-MS } & \text { Inductively coupled plasma mass spectroscopy } \\ \text { GAE } & \text { Gallic acid equivalents } \\ \text { ORAC } & \text { Oxygen radical absorbance capacity } \\ \text { TE } & \text { Trolox equivalents } \\ \text { ANOVA } & \text { Analysis of variance } \\ \text { GSH } & \text { Glutathione } \\ \text { ROS } & \text { Reactive oxygen species }\end{array}$




\subsection{Literature Review:}

Selenium Biofortification of Agricultural Crops and Effects on Plant Nutrients and Bioactive Compounds Important for Human Health and Disease Prevention

Rachel Newman ${ }^{1}$, Nicole Waterland ${ }^{2}$, Youyoun Moon ${ }^{2}$, Janet C. Tou ${ }^{1}$

${ }^{1}$ Division of Animal and Nutritional Sciences, West Virginia University

${ }^{2}$ Division of Plant and Soil Sciences, West Virginia University

Corresponding Author:

Janet C. Tou, PhD

Division of Animal and Nutritional Sciences

West Virginia University

Morgantown, WV 26506

Tel: (304)293-1919

Fax: (304)293-2232

e-mail: janet.tou@mail.wvu.edu 


\subsection{Introduction}

Selenium (Se) is an essential dietary trace mineral and a component of biologically important selenoproteins [1]. In the human body, selenoproteins are involved in thyroid hormone metabolism, immune function, and antioxidant defenses [2]. It is estimated that half a billion to one billion people worldwide are Se-deficient [3]. In North America, Se deficiency is uncommon; although, vegans living in areas with low-Se soil and individuals with human immunodeficiency virus or in various stages of chronic kidney disease are at risk [4-6]. In countries where Se intake is adequate, interest in Se has focused on its potential to prevent and manage chronic diseases [1]. To achieve these health benefits, it has been suggested that Se intake should exceed the adult recommended dietary allowance (RDA) of $55 \mu \mathrm{g} \cdot$ day $^{-1}$, while remaining below the tolerable upper intake level (UL) of $400 \mu \mathrm{g} \cdot \mathrm{day}^{-1}$ [1].

Enhancing Se uptake by edible plants during growth through biofortification can provide supplemental levels of Se to the human diet. Plants exhibit varying levels of Se tolerance instead of essentiality [7]. Therefore, the goal of Se biofortification is to meet a balance between increasing Se content in the plants while avoiding significant decreases in crop yield [8]. From a human nutrition perspective, successful Se biofortification should increase Se content without impacting other nutrients and bioactive compounds important to human health that are naturally present in plants. Studies have reported that Se uptake by plants can affect other dietary minerals and antioxidant compounds [9-13]. Therefore, the nutritional significance of Se biofortification extends beyond increasing plant Se content.

Several published reviews have addressed Se biofortification from the plant standpoint of Se speciation, application methods, dose for maximizing uptake, and effect on plant biomass [8, 14]. The aim of this review is to focus on human nutrition by addressing the impact of Se 
biofortification on plant Se content as well as other plant constituents of dietary importance to human health.

For review purposes, adjustments to treatment doses and Se content were made to allow for comparison of data from different plant biofortification studies. Se content was reported in $\mathrm{mg} \cdot \mathrm{kg}^{-1}$ dry weight (DW) and converted as necessary. Conversions from fresh weight (FW) values were based on water content percentages from the United States Department of Agriculture Food Composition Database for the specific plant species [15]. Se treatment doses were converted to $\mu \mathrm{M}$ Se for hydroponic and foliar applications; however, due to heterogeneity of studies, soil application doses were left as reported by the study authors.

\subsection{Role of Selenium in Health and Disease Prevention}

Overt Se deficiency $\left(\leq 13 \mu \mathrm{g} \cdot \mathrm{day}^{-1}\right)$ contributes to Keshan disease, a potentially fatal cardiomyopathy primarily affecting children [16]. Chronic failure to meet recommended Se intake produces a myriad of symptoms including: hypothyroidism, subfertility, weakened immune system and increased susceptibility to viral infections [2]. On the other hand, intakes of Se higher than the recommended amount have been suggested to prevent chronic diseases particularly, cardiovascular disease (CVD), neurodegeneration diseases, and cancer [2, 17].

The Cochrane review assessing Se supplementation and cancer incidence consists of ten randomized controlled trials (RCT) with 27,232 participants [18]. In studies with low risk of bias, the review concluded Se supplementation (range 200-400 $\mu \mathrm{g} \cdot \mathrm{day}^{-1}$ ) had no significant effect on cancer incidence [relative risk (RR), 1.01; 95\% confidence interval (CI), 0.93-1.10; 3 studies, 19,475 participants] or cancer mortality (RR, 1.02; 95\% CI, 0.80-1.30; 1 study 17,444 participants) (Table 1). The most frequently studied site-specific cancers, including lung, colorectal, breast, prostate, and non-melanoma skin cancer, also reported no beneficial effects. 
Similarly, the Selenium and Vitamin E Cancer Prevention Trial (SELECT) enrolling 35,533 men found no significant effect of Se supplementation [hazard ratio (HR), 1.04; 99\% CI, 0.87-1.24] or Se + vitamin E supplementation (HR, 1.05; 99\% CI, 0.88-1.25) on prostate cancer incidence compared to placebo at 4.17 to 7.33 years follow-up. Se was supplemented at a dose of 200 $\mu \mathrm{g} \cdot \mathrm{day}^{-1}$ as L-selenomethionine [19] (Table 1). It is relevant to note that supplemental doses in RCTs are provided without consideration for dietary Se intake. Supplementation of Se in high doses of 200-400 $\mu \mathrm{g} \cdot \mathrm{day}^{-1}$ in combination with an adequate intake of dietary Se may result in a total daily intake that approaches or exceeds the established UL of $400 \mu \mathrm{g} \cdot \mathrm{day}^{-1}$. In contrast to the SELECT trial, the Nutritional Prevention of Cancer Trial (NPCT) provided $200 \mu \mathrm{g} \cdot \mathrm{day}^{-1} \mathrm{Se}$ as Se-enriched yeast which significantly reduced incidence of lung, colorectal, and prostate cancer, total cancer incidence $(\mathrm{RR}, 0.63 ; 95 \% \mathrm{CI}, 0.47-0.85 ; p=0.001)$ and total cancer mortality (RR, 0.50; 95\% CI, 0.31-0.80; $p=0.002$ ) [20] (Table 1). Benefits of Se supplementation in the NPCT study may be due to a lower Se status of participants compared to participants in the SELECT study. Further, Se has been reported to be more bioavailable when provided as yeast than as purified selenomethionine supplement [21]. Yeast is rich in B vitamins as well as in minerals that function as cofactors for endogenous antioxidants in both plants and animals such as: iron $(\mathrm{Fe})$, copper $(\mathrm{Cu})$, zinc $(\mathrm{Zn})$, manganese $(\mathrm{Mn})$ [22].

In pre-clinical studies, consumption of Se-enriched yeast reduced chemically-induced colorectal cancer in a rat model [23]. Other pre-clinical studies also reported chemoprotective effects with Se-enriched food intake [24-27]. Feeding rats Se-biofortified garlic (Allium sativum) was more effective than Se-enriched yeast supplementation for inhibiting chemically-induced mammary gland tumors [25]. Feeding rats Se-biofortified broccoli (Brassica oleracea var. Italica) was more effective for reducing chemically-induced colon cancer than either selenate or 
selenite supplementation [26]. Se-biofortified broccoli consumption also resulted in significantly fewer intestinal tumors in mice when compared to the intake of equivalent amounts of nonbiofortified broccoli [27]. Collectively, results of pre-clinical studies emphasize the benefits of consuming Se in food form rather than in purified form.

Regarding the role of Se in neurodegenerative diseases, the Prevention of Alzheimer's Disease by Vitamin E and Selenium trial (PREADViSE) involved 7,338 men and concluded no significant effect of Se supplementation (HR, 0.83; 95\% CI, 0.60-1.13) or vitamin $\mathrm{E}+\mathrm{Se}$ supplementation (HR, 1.00; 95\% CI, 0.75-1.35) on dementia incidence compared to placebo (Table 1). A dose of $200 \mu \mathrm{g} \cdot$ day $^{-1} \mathrm{~L}$-selenomethionine was used since PREADiVSE was an ancillary study of the SELECT study [28]. On the other hand, intake of leafy greens and other vegetables have shown strong evidence of an association with neuroprotective effects [29]. Plants are rich sources of nutrients shown to benefit Alzheimer's disease, such as folate, vitamin E, carotenoids, polyphenols, and polyunsaturated fatty acids [29, 30], providing further support for Se-biofortified plants as a preferred source for increased Se consumption.

Similar to the results of cancer and neurodegenerative disease studies, Se supplementation effects on CVD has also been inconclusive. A meta-analysis of 9 RCTs involving 36,511 participants concluded Se-enriched yeast and L-selenomethionine supplementation at Se doses of 75 to $300 \mu \mathrm{g} \cdot$ day $^{-1}$ had no significant effect on cardiovascular incidence [31] (Table 1). Another meta-analysis consisting of 16 RCTs with 43,998 reported a trend [Odds ratio (OR), $0.88 ; 95 \% \mathrm{CI}, 0.76-1.02 ; p=0.087 ; 8$ studies; 41,763 participants] for reduced coronary heart disease mortality with Se supplementation [32]. Subgroup analysis found when Se supplementation was combined with supplementation of other vitamins and minerals, there was reduced risk of coronary heart disease mortality $(\mathrm{OR}, 0.86$; 95\% CI, 0.74-1.00; $p=$ 
0.05) [32]. Se supplementation reduced oxidative stress and inflammation based on findings of increased $(p<0.001)$ serum glutathione peroxidase (GSH-Px), a selenoprotein enzyme involved in regulation of oxidative processes [1] and decreased $(p=0.049)$ serum C-reactive protein (CRP). However, results indicated that Se supplementation alone is not sufficient to reduce coronary heart disease mortality and other vitamins and minerals can provide added benefits when supplemented with Se. Doses used in these studies were higher (75 to $500 \mu \mathrm{g} \cdot \mathrm{day}^{-1}$ ) than the RDA of $55 \mu \mathrm{g} \cdot \mathrm{day}^{-1}$ with an exception of one study $\left(50 \mu \mathrm{g} \cdot \mathrm{day}^{-1}\right)$ [32] (Table 1).

Collectively, studies of Se supplementation alone or with vitamin E supplementation found no improvement of CVD, cancer or neurodegenerative diseases, but had beneficial effects when combined with several other nutrients. Biofortification of plants offers the advantage of providing higher Se as well as other antioxidant and anti-inflammatory constituents that are naturally present in plant foods such as essential minerals and polyphenols.

\subsection{Effects of Biofortification on Plant Selenium Content}

From a human nutrition perspective, Finland provides a model of a Se biofortification program that has been successfully used to address a public health issue. In Finland, addition of sodium selenate to multi-nutrient fertilizers began in 1985 when Se intake in the Finnish population was less than $40 \mu \mathrm{g} \cdot \mathrm{day}^{-1}$ [33]. By 1991, the average Se intake was approximately 120 $\mu \mathrm{g} \cdot$ day $^{-1}$, surpassing the RDA [33]. Sodium selenate addition to fertilizers proved to be an effective and safe method for increasing the amount of Se in food and in the human diet. While soil fertilization with sodium selenate was used in Finland, Se biofortification generally utilizes either sodium selenate or sodium selenite and various application techniques including soil addition, foliar/fruit spraying, and hydroponic nutrient solutions [8]. The use of hydroponics in Se biofortification has been increasingly studied due to benefits over other application techniques. Hydroponics avoids direct addition to soils which addresses the concern of high soil 
Se acting as an environmental contaminant [34]. Further, soil application of Se introduces confounding factors, such as adsorption with soil colloidal surfaces resulting in less Se available to the plants [34]. Hydroponics allows for a controlled application of Se by supplying a specific concentration to the nutrient solution [8].

Selenate is preferred over selenite because of superior translocation to edible parts of the plant [7, 34]. Hawrylak-Nowak [9] compared the effects of selenate and selenite on Se accumulation in the edible portion of lettuce plants (Lactuca sativa L. var. Capitata 'Justyna') grown under hydroponic conditions with Se concentrations of 2.0, 4.0, 6.0, 15.0 $\mu \mathrm{M}$. The translocation factor (the ratio of Se content in shoots to roots) ranged from 0.69 to 2.47 for selenate and $<0.15$ for selenite, demonstrating selenite's poor translocation in plants. Concentrations of 2.0 to $15.0 \mu \mathrm{M}$ Se as selenate resulted in higher $(p<0.05)$ Se accumulation in lettuce shoots ranging from 4.7 to $43.3 \mathrm{mg} \cdot \mathrm{kg}^{-1} \mathrm{DW}$ compared to selenite, which resulted in a Se accumulation range of 3.7 to $30.6 \mathrm{mg} \cdot \mathrm{kg}^{-1} \mathrm{DW}$. Further, when higher dosages were tested (up to $60.0 \mu \mathrm{M} \mathrm{Se})$, selenite caused a significant decrease in plant biomass at a lower dose $(15.0 \mu \mathrm{M}$ Se) than selenate $(20.0 \mu \mathrm{M} \mathrm{Se})$. This trend of toxicity at lower doses for selenite than selenate is a common observation in Se biofortification studies [8].

Another important consideration when choosing which plant to biofortify is that plants vary with respect to their capacity for Se uptake and tolerance. Brassica and Allium species accumulate more Se due to their high content of sulfur (S) compounds $[1,8]$. Because Se and $\mathrm{S}$ are chemically similar, the uptake, translocation, and metabolism of Se in plants parallels that of S [8]. A review of Se biofortification of Brassica vegetables included 42 studies using different Se doses, speciation, and application methods found hydroponic cultures achieved the highest Se accumulation. Of the Brassica vegetables studied, broccoli (Brassica oleraca L. var. Italica), 
Indian mustard (Brassica juncea L. Czern), and rapid cycling cabbage (Brassica oleracea var. Capitata) accumulated the highest Se content (range 1,800-1,900 $\mathrm{mg} \cdot \mathrm{kg}^{-1} \mathrm{DW}$ in shoot tissue) [14]. However, most crop plants are low rather than high Se accumulators [14]. Another review of Se biofortification of leafy vegetables included 21 studies using different Se doses, speciation, and application methods. Se content in the edible parts of lettuce (Lactuca sativa L.), chicory (Chicorium intybus L.), basil (Ocimum basilicum L.), and spinach (Spinacia oleracea L.) supplemented with Se through enrichment of the nutrient solution ranged from 10.0 to 3890 $\mathrm{mg} \cdot \mathrm{kg}^{-1} \mathrm{DW}$. Spinach was found to accumulate up to $3890 \mathrm{mg} \cdot \mathrm{kg}^{-1} \mathrm{Se}$ DW when supplied with a higher dose $(126.6 \mu \mathrm{M})$ of Se than the other plant species [8].

When planning Se biofortification for specific plant species, time to harvest should also be considered to determine timing for maximum Se uptake. Puccinelli et al. [35] investigated Se uptake in basil (Ocimum basilicum L.) leaves grown in hydroponic conditions followed by harvest at $0,13,27,41,55$, and 69 days of treatment. Se was supplied to basil plants at concentrations of $0.0,50.7,101.3$, and $152.0 \mu \mathrm{M}$. Plants grown in concentrations of 101.3 and 152.0 $\mu \mathrm{M}$ Se reached a maximum Se content at an earlier harvesting time of 27 days than the $50.7 \mu \mathrm{M}$ Se treatment group at 41 days. This maximum uptake at earlier days of harvest may be attributed to higher Se concentrations inducing faster Se uptake rates. Once maximum Se uptake was reached for each treatment, a gradual decline of Se concentration in leaves was observed. This decrease was suggested to be the result of increased plant growth causing a "dilution effect" of Se content [35]. The results from this study indicate the existence of an optimal Se treatment time frame and ideal harvest time.

From a plant perspective, it is important that the Se dose used to maximize plant Se content not be detrimental to crop yield. For example, Rios et al. [36] observed positive effects 
of sodium selenate treatment on lettuce (Lactuca sativa L. 'Philipus') biomass at a concentration range of 5.0 to $20.0 \mu \mathrm{M}$ Se, but reduced biomass at a range of 60.0 to $120.0 \mu \mathrm{M}$ Se. Ultimately, the purpose of Se biofortification is to improve the nutritional value of plants for human consumption. Therefore, the impact of Se biofortification on other plant nutrients and bioactive components relevant to human health is important to investigate.

\subsection{Effects of Biofortification on Minerals Relevant to Human Health}

In the United States, calcium $(\mathrm{Ca})$, magnesium $(\mathrm{Mg})$, potassium $(\mathrm{K})$, and $\mathrm{Fe}$ are underconsumed nutrients [37]. Therefore, potential fluctuations of these dietary minerals with Se biofortification of plants are particularly important to investigate. Ca is essential for bone formation; therefore, chronic low Ca intake contributes to osteoporosis [38]. Saffaryazdi et al. [10] examined the effect of sodium selenite biofortification in hydroponic conditions on $\mathrm{Ca}$ content in spinach (Spinacia oleracea L. 'Missouri') plants. Se doses of 12.7, 25.3, and $50.7 \mu \mathrm{M}$ increased $(p \leq 0.05)$ Ca content in the shoots of spinach plants by $69.0,81.3$, and $74.2 \%$ compared to no Se treatment (Table 2). He et al. [11] showed that $1.0 \mathrm{mg} \cdot \mathrm{kg}^{-1} \mathrm{Se}$ supplied as sodium selenite to soil increased Ca content in Chinese cabbage (Brassica rapa) and lettuce (Lactuca sativa L.). Ca content was significantly increased by $13.7 \%$ in Chinese cabbage and by $2.8 \%$ in lettuce compared to plants not treated with Se [11]. Both studies' results demonstrated Se biofortification as selenite had beneficial effects on Ca content of plants, although the extent of Ca increase varied among plant species. Based on these results, Ca content generally increases with selenite biofortification for hydroponic and soil applications. Rios et al. [39] considered lettuce (Lactuca sativa L. 'Philipus') grown in hydroponic conditions with Se supplied in the nutrient solution as both selenite and selenate at doses ranging from 5.0 to $120.0 \mu \mathrm{M}$. Results showed Ca content of the lettuce was significantly different among doses for both selenite and 
selenate $(p<0.01$ and $p<0.001$, respectively). However, the authors noted a general decrease in lettuce $\mathrm{Ca}$ content for both species of Se compared to control plants $(0.0 \mu \mathrm{M} \mathrm{Se})$.

$\mathrm{Mg}$ is another mineral important for maintaining bone health. Additionally, low Mg intake has been associated with migraine headaches and increased risk of CVD and type 2 diabetes [40]. Boldrin et al. [12] reported soil application of $0.75 \mathrm{mg} \cdot \mathrm{kg}^{-1}$ Se to rice (Oryza sativa L. 'BRSMG Relâmpago') as sodium selenate and sodium selenite resulted in significantly higher $\mathrm{Mg}$ compared to $0.0 \mathrm{mg} \cdot \mathrm{kg}^{-1} \mathrm{Se}$ (Table 2). Conversely, foliar application as either selenate or selenite with a dose of $50.0 \mu \mathrm{M}$ Se did not significantly alter $\mathrm{Mg}$ content in rice [12]. Absence of significant effects on rice $\mathrm{Mg}$ content with foliar application of Se may be attributed to shorter $\mathrm{Se}$ exposure compared to soil application. Overall, $\mathrm{Mg}$ content demonstrates increases and no changes for soil and foliar applications but decreases for both selenate and selenite in hydroponic conditions [39]. Collectively, results indicate that the application methods used in Se biofortification are important to consider since not only is Se content affected, but content of other plant minerals are also impacted.

Western diets are also low in $\mathrm{K}$ due to decreased fruit and vegetable consumption with a concomitant increase in sodium (Na) intake from processed foods [41]. Na surfeit combined with K deficiency has been associated with hypertension, a risk factor for CVD [42]. Saffaryazdi et al. [10] showed selenite at a dose of $76.0 \mu \mathrm{M}$ Se decreased K by $27.7 \%$, and at the higher Se dose of $126.6 \mu \mathrm{M}, \mathrm{K}$ content decreased by $31.4 \%$ in hydroponically-grown spinach shoots compared to untreated spinach (Table 2). Reduction in dietary minerals is especially concerning when the fortified food is a dietary staple that supplies a large proportion of minerals to the diet. Rice (Oryza sativa) and wheat (Triticum spp.) have been targeted for Se biofortification since these crops are staple foods for over half of the world's population [43]. However, in a Western 
population already at a dietary deficit of fruits and vegetables, decreases in $\mathrm{K}$ content of staple crops can contribute to the development of high blood pressure.

$\mathrm{Se}$ as well as other trace minerals $\mathrm{Mn}, \mathrm{Zn}, \mathrm{Fe}$, and $\mathrm{Cu}$ function as cofactors for human endogenous antioxidant enzymes [44]. Se biofortification effects on these trace minerals suggest that Se-biofortified foods can alter antioxidant capacity. Boldrin et al. [12] reported that soil selenate biofortification at $0.75 \mathrm{mg} \cdot \mathrm{kg}^{-1} \mathrm{Se}$ significantly increased both $\mathrm{Mn}$ and $\mathrm{Zn}$ content in rice grains compared to untreated rice (approximately 52.4 and 17.2\% increases, respectively). Mn content typically increases or remains unchanged with Se biofortification while $\mathrm{Zn}$ predominantly demonstrates nonsignificant changes in content (Table 2). Soil application of either selenate or selenite did not significantly affect rice Fe content, but foliar application of selenate at $50.0 \mu \mathrm{M}$ Se significantly increased Fe content by approximately $23.1 \%$ [12] (Table 2), again emphasizing the importance of Se application methods. In contrast, He et al. [11] found soil selenite biofortification at a dose of $1.0 \mathrm{mg} \cdot \mathrm{kg}^{-1} \mathrm{Se}$ significantly reduced Fe content by 21.9\% in lettuce and by 55.1\% in Chinese cabbage. Rios et al. [39] showed increases in Fe content of lettuce for both selenate and selenite added to the hydroponic nutrient solution with Se doses ranging from 10.0 to $120 \mu \mathrm{M}$. In general, Fe content increases with hydroponic applications of Se, but decreases or is unaffected with soil supplementation (Table 2). He et al. [11] also reported selenite application to soil significantly decreased $\mathrm{Cu}$ content by $6.1 \%$ in lettuce and $32.1 \%$ in Chinese cabbage compared to plants not treated with Se (Table 2). $\mathrm{Cu}$ content tends to decrease or remain unchanged with Se biofortification; although, Rios et al. [39] reported increases of $\mathrm{Cu}$ in lettuce grown hydroponically with sodium selenite (Table 2).

Table 2 summarizes findings of Se biofortification on minerals of relevance to human health. Studies showed uptake of several minerals important to human health can be either 
positively or negatively affected by Se biofortification. It is important to identify which dietary minerals are negatively impacted and by how much to determine whether this can result in significantly lower dietary intakes. The effect on minerals is unique among plant species based upon application method and may require optimization of Se biofortification techniques for individual plant species. To avoid potentially reducing intake of other important dietary minerals, Se biofortification should prioritize foods that are not dietary staples or that do not supply a large proportion of minerals to the diet. Choosing which food crops to biofortify with Se becomes more complicated when considering effects on other minerals. Currently, there is high variability in application techniques used in studies that measure relevant minerals, so specific recommendations cannot be made without further research.

From a human dietary perspective, $\mathrm{S}$ is not a mineral of concern. However, $\mathrm{S}$ is important to analyze because selenate is taken up by plants through sulfate transporters [7]. HawrylakNowak [9] reported lettuce plants grown in hydroponic conditions with $15.0 \mu \mathrm{M}$ Se as selenate resulted in a significant increase (101.7\% increase) of sulfur content in the shoots of lettuce plants compared to control $(0.0 \mu \mathrm{M} \mathrm{Se})$. In plants, changes in $\mathrm{S}$ assimilation by $\mathrm{Se}$ biofortification affect synthesis of amino acids such as: methionine, tyrosine, tryptophan, and phenylalanine which are precursors for plant biosynthesis of cancer-protective glucosinolates [13]. Phenylalanine is also the precursor for plant biosynthesis of antioxidant phenolics [13].

\subsection{Effects of Biofortification on Antioxidants Relevant to Human Health}

Plants contain vitamins and polyphenols that demonstrate antioxidant, anti-inflammatory, and anti-proliferative activity, suggesting anti-cancer and cardioprotective roles in humans [45]. Several studies have reported that Se biofortification increased antioxidant enzyme activity in 
plants [8]. Therefore, the impact of Se biofortification on plant antioxidant constituents needs to be considered.

Rios et al. [36] investigated the impact of hydroponic Se biofortification of lettuce on vitamin $\mathrm{C}$, which acts as an antioxidant by neutralizing free radicals and enhancing the regeneration of another antioxidant, vitamin E [46]. As the added Se concentration for both selenate and selenite in hydroponics increased from 0.0 to $120.0 \mu \mathrm{M}$, vitamin $\mathrm{C}$ content of lettuce increased $285.1 \%$ for selenate and $217.7 \%$ for selenite (Table 3 ). The study also observed that Se biofortification using concentrations of 5.0, 10.0, and $20.0 \mu \mathrm{M}$ for selenate and $5.0 \mu \mathrm{M}$ for selenite increased shoot biomass compared to lettuce treated with $0.0 \mu \mathrm{M}$. At Se concentrations of $40.0 \mu \mathrm{M}$ for selenate and $10.0 \mu \mathrm{M}$ for selenite, there was no significant effect on plant biomass, while at higher concentrations, biomass began to decrease up to the $120.0 \mu \mathrm{M}$ dose. Based on these results, the use of selenate within a certain dose range in hydroponic conditions may offer the benefits of increasing vitamin $\mathrm{C}$ content without diminishing crop yield. Selenate's ability to improve vitamin C content of crops has also been reported in other studies using different application techniques and plant species. Zhu et al. [47] used foliar application of $12.7 \mu \mathrm{M}$ Se as selenate to treat tomato plants (Solanum lycopersicon $\mathrm{L}$. 'Provence') at the onset of flowering and measured the effect on vitamin $\mathrm{C}$ content during postharvest storage. Se-treated tomatoes harvested at mature green stages had higher $(p<0.05)$ vitamin $\mathrm{C}$ content than untreated tomatoes at all storage days $(0,5,10,15$, and 20) (Table 3$)$. While different application techniques and plant species can affect Se accumulation, it is noteworthy that vitamin $\mathrm{C}$ content increased in both hydroponic and foliar applications.

Se biofortification can also influence anthocyanins, another specific class of flavonoids known for their potent antioxidant and anti-inflammatory activities [45]. Liu et al. [48] showed 
that anthocyanin content of purple lettuce (Lactuca sativa L. 'Purple Rome') increased significantly with sodium selenite treatment in hydroponic conditions with 4.0 and $8.0 \mu \mathrm{M}$ doses but was not affected at 12.0 $\mu \mathrm{M}$. However, lettuce at the $16.0 \mu \mathrm{M}$ Se dose demonstrated a significant decrease of anthocyanin content. Hawrylak-Nowak [49] used foliar application of selenate at different doses $(12.7,38.0,63.3,126.6,253.3,633.2 \mu \mathrm{M})$ on basil plants (Ocimum basilicum L.). Anthocyanin content in basil was significantly increased at Se doses of 126.6, 253.3, and 633.2 $\mu \mathrm{M}$ compared to $0.0 \mu \mathrm{M}$ with increases of $72.7,159.1$, and $209.1 \%$, respectively [49]. While anthocyanins at Se doses of 253.3 and $633.2 \mu \mathrm{M}$ were significantly higher compared to $126.6 \mu \mathrm{M}$, there was no significant difference of anthocyanin content between 253.3 and $633.2 \mu \mathrm{M}$. The results from purple lettuce and basil studies indicate that anthocyanins do not increase beyond a threshold dosage of applied Se (Table 3).

Se biofortification with selenate using different application techniques also enhanced phenol content in various plant species. Hawrylak-Nowak [49] showed total phenols were significantly enhanced in basil leaves at foliar selenate doses of 38.0, 63.3, 126.6, 253.3 $\mu \mathrm{M}$ compared to control plants treated with distilled water. The dose of $63.3 \mu \mathrm{M}$ Se resulted in the largest increase of total phenol content by $43.9 \%$. The lowest dose of $12.7 \mu \mathrm{M}$ Se and the highest dose of $633.2 \mu \mathrm{M}$ Se had no significant effect on phenolic content. The results suggested a Ushaped relationship of Se biofortification and phenolic content (Table 3).

Saffaryazdi et al. [10] analyzed the effect of sodium selenite on phenolic compounds in the shoots of spinach plants grown in hydroponics. Se doses of 50.7, 76.0, and 126.6 $\mu \mathrm{M}$ applied as selenite increased total phenolic content (approximately 43.1, 38.5, 53.9\%, respectively) compared to $0.0 \mu \mathrm{M}$. Results showed that Se added as selenite in hydroponics has potential to increase important antioxidant compounds in biofortified crops (Table 3). Another study [36] 
investigated both selenite and selenate biofortification on antioxidant compounds in lettuce plants grown in hydroponic conditions. Compared to control, the highest Se dosage of $120.0 \mu \mathrm{M}$ increased phenols by 122.2 and $105.6 \%$ in selenite and selenate treatments, respectively. Further, flavonoids increased by 241.7 and $247.2 \%$ in selenite and selenate treatments, respectively (Table 3). However, the difference between selenate and selenite was not significant for these antioxidant compounds, and there was no apparent advantage of using selenate compared to selenite on total phenol and flavonoid content.

Vinson et al. [50] determined phenols in 23 commonly consumed vegetables in the United States. Tomatoes, while not naturally highest in phenols, ranked highest as the leading source of phenols in the American diet. Schiavon et al. [51] investigated Se foliar application of 0, 2.0 or $20.0 \mathrm{mg}$ Se per plant on Se uptake and antioxidant constituents in tomato plants (Solanum lycopersicon L.). Tomato fruits treated with doses of 2.0 and $20.0 \mathrm{mg}$ Se resulted in Se content of 19.0 and $256.0 \mathrm{mg} \cdot \mathrm{kg}^{-1} \mathrm{FW}$, respectively. Se biofortification of tomato plants reduced identified phenolic acids, while naringenin chalcone, which was the most abundant flavonoid, increased significantly by $329.1 \%$ at the $20.0 \mathrm{mg}$ Se dose. The authors suggest that the phenylpropanoid metabolism shifted from phenolic acids to the synthesis of flavonoids [51]. Based on the results, Se biofortification enriched edible parts of tomatoes with naringenin chalcone. This is significant to human health since chalcones have been studied for their antineoplastic, anti-hypertensive, anti-inflammatory, and anti-diabetic activities [52].

Glucosinolates and isothiocyanates are other plant compounds that act as antioxidants, decreasing free radicals indirectly by triggering the transcription of phase II metabolic enzymes or directly by scavenging peroxides [53] As a thiol, glucosinolates can be affected by $\mathrm{Se}$ biofortification due to the similarity between Se and S [13]. Rapid-cycling Brassica oleracea 
species grown hydroponically reported total glucosinolates in leaf tissue significantly decreased as Se treatment increased, with a $63.6 \%$ decrease existing at the $40.5 \mu \mathrm{M}$ dose compared to 0.0 $\mu \mathrm{M}$ [54] (Table 3). Increasing Se concentration from 0.0 to $40.5 \mu \mathrm{M}$ also significantly decreased total isothiocyanates by $74.9 \%$ in B. oleracea [54]. This is significant to human health since isothiocyanates are glucosinolate degradation products linked to chemoprotective properties of Brassica vegetables [54]. Both studies showed that high Se content in plants can negatively impact the metabolism of other important plant antioxidants.

Different stages of plant maturity affect the antioxidant response to Se biofortification. Ávila et al. [55] investigated the effect of $25.0 \mu \mathrm{M}$ Se as sodium selenate biofortification on mature broccoli (Brassica oleracea L. Italica) florets grown in soil in a greenhouse and broccoli sprouts grown in hydroponic conditions in growth chambers. In general, Se biofortification produced 6.5-fold higher total Se in mature broccoli florets than in the sprouts. The authors estimated that consuming a serving of $7.20 \mathrm{~g}$ of fresh sprouts or $1.12 \mathrm{~g}$ of fresh florets of broccoli treated with $25.0 \mu \mathrm{M}$ Se can meet the RDA for Se. On the other hand, Se biofortification suppressed glucosinolate accumulation in the mature florets, but had minimal effect on glucosinolate content in sprouts (Table 3). Compared to sprouts, broccoli florets had 6-fold lower content of glucoraphanin, a specific glucosinolate known for anticancer properties [55]. Glucoraphanin is metabolized to isothiocyanate sulforaphane, a monoinducer of phase II enzymes in inactivating carcinogenic metabolites [55]. Thus, a serving of $7.20 \mathrm{~g}$ of fresh Sebiofortified sprout provides $17.12 \mathrm{mg}$ of glucoraphanin while $1.12 \mathrm{~g}$ of fresh florets provides only $0.32 \mathrm{mg}$ of glucoraphanin. Based on the study results, broccoli floret accumulated more $\mathrm{Se}$, but at the expense of glucosinolate loss compared to sprouts. 
In another study, Ávila et al. [56] investigated the effect of Se biofortification on the sprouts of cultivars of the six most extensively consumed Brassica vegetables: Brussel sprouts (Brassica oleracea L. var. Gemmifera), broccoli (Brassica oleracea L. var. Italica), cauliflower (Brassica oleracea L. var. Botrytis), kale (Brassica oleracea L. var. Acephala), green cabbage (Brassica oleracea L. var. Capitata), and Chinese cabbage (Brassica rapa L. ssp. Pekinensis). Se was added to water at a concentration of $50.0 \mu \mathrm{M}$ as sodium selenate during gemination and sprout growth. Results showed similar Se accumulation among sprouts of different Brassica crops, with Brussels sprouts demonstrating the lowest capacity at accumulating Se. Despite different types and amounts of glucosinates among Brassica vegetables, total glucosinolate accumulation was not significantly different in Se-biofortified Brassica sprouts compared to the sprouts grown in only water, with an exception of a significant increase in two cauliflower cultivars ('Graffiti' and 'Absolute') and a decrease in two Chinese cabbage cultivars ('Tender Gold' and 'Beijing Autumn 56') (Table 3). Based on the results, the authors concluded that Brassica vegetable sprouts can be biofortified with $50 \mu \mathrm{M}$ Se without negatively affecting glucosinolate content.

Table 3 summarizes the effects of Se biofortification on various antioxidant compounds. Generally, studies evaluating the effects of Se biofortification on antioxidants in edible plants reported significant increases in vitamin $\mathrm{C}$, total phenols, anthocyanins, and flavonoids. This suggests that Se-biofortified foods can be beneficial to human health not only for enhanced Se intake, but for increasing intake of disease-preventative phytochemicals. However, studies have also shown that excessive levels of Se treatment may incur a negative effect on antioxidants in plants $[48,49]$. Existence of a threshold for antioxidant enhancement is supported by the observation that Se begins to function as a pro-oxidant in plants at excessively high 
concentrations [8]. The effect of Se biofortification on glucosinolates was negative even with low doses. Se biofortification of sprouts instead of mature plants may prevent this negative effect on glucosinolate content while still delivering supplemental intakes of Se in the diet. Therefore, the ideal Se biofortification application should maximize Se and antioxidant compounds in the plants without detrimental effects on crop yield.

\subsection{Consumption of Selenium-Biofortified Plants on Human Health}

The impact of Se-biofortified plants on nutritional status and health benefits in humans has not been extensively studied. One study investigated the effect of Se-biofortified wheat (Triticum spp.) consumption on Se status and potential health benefits in men $(n=14)$ and women $(\mathrm{n}=16)$ with a broad age range $(19-86$ years old) [57]. Participants described as Sedeficient were provided Se-biofortified wheat products for six weeks. The wheat used for consumption in this study was biofortified by foliar application which increased Se content by

five fold, on average. Results showed consumption of Se-biofortified wheat products increased Se intake by $12-35 \mu \mathrm{g} \cdot \mathrm{day}^{-1}$. Compared to baseline, plasma GSH-Px and erythrocyte GSH-Px increased by $83.5 \%$ and $37.3 \%$, while lipid peroxidation product, thiobarbituric acid reactive substances, decreased. A modest improvement in CVD risk factors was indicated by a $10.3 \%$ reduction in total cholesterol, $14.5 \%$ reduction in triglycerides, and $15.1 \%$ reduction in low density lipoprotein [57]. However, the statistical significance of these results was not indicated in this study.

Another study investigating Se-biofortified wheat consumption consisted of healthy men ( $\mathrm{n}=62$, age 40 to 70$)$ considered to have adequate plasma Se levels $\left(122 \mu \mathrm{g} \cdot \mathrm{L}^{-1}\right)$ [58]. Foliar sodium selenate application to wheat (Triticum spp.) resulted in an increase to $10 \mathrm{mg} \cdot \mathrm{kg}^{-1} \mathrm{Se}$ compared to $0.07 \mathrm{mg} \cdot \mathrm{kg}^{-1} \mathrm{Se}$ in untreated wheat. $\mathrm{Ca}, \mathrm{Mg}, \mathrm{Fe}, \mathrm{Zn}, \mathrm{Mn}, \mathrm{Cu}$ and $\mathrm{S}$ content were 
similar between the two wheat treatments. Daily consumption of this biofortified wheat with $\mathrm{Se}$ dosages up to $267 \mu \mathrm{g}$ for 24 weeks resulted in a peak plasma Se concentration of $193 \mu \mathrm{g} \cdot \mathrm{L}^{-1}$. The men in this study had adequate Se status, and consuming Se-biofortified wheat biscuits showed no significant effect on platelet GSH-Px activity, lipid, lipoprotein profile, or CRP compared to baseline. Results of studies by Djujic et al. [57] and by Wu et al. [58] showed Se-biofortified wheat consumption increased Se status markers. However, the effect on oxidative stress and CVD risk factors were inconsistent, highlighting the need for further human intervention studies.

A meta-analysis compared the effectiveness of supplementing Se-biofortified foods and other Se forms on activity of GSH-Px, concluding Se-enriched foods increased GSH-Px activity more effectively than selenomethionine in animals [59]. Of the seventeen human studies identified in the meta-analysis, only four studies met the selection criteria for inclusion in the review, and a significant effect of form of Se on GSH-Px activity in humans was not observed (Table 1). However, onions were the only Se-biofortified plant food considered in the four human studies. Based on the small number of studies, the analysis was regarded as preliminary for humans [59]. Biofortified foods have the potential to exert additional benefits besides optimizing Se status due to enhanced antioxidant compounds. Therefore, studies that compare the health benefits of Se-biofortified foods to conventional foods are needed to fully assess the potential of biofortification in human health. Future studies with larger numbers of participants can determine the potential of Se-biofortified foods in disease prevention for the general population.

While crop plants such as wheat typically accumulate a maximum of $100 \mathrm{mg} \cdot \mathrm{kg}^{-1} \mathrm{Se} \mathrm{DW}$, Se secondary accumulators such as Brassica and Allium plants can accumulate up to 1,000 $\mathrm{mg} \cdot \mathrm{kg}^{-1} \mathrm{Se}$ DW $[7,8]$. In choosing which crop to biofortify with Se, the recent published 
findings of the Demark PRECISE study need to be taken into consideration. Results showed men and women taking a supplemental Se dose of $300 \mu \mathrm{g} \cdot \mathrm{day}^{-1}$ as Se-enriched yeast for 5 years had increased all-cause mortality compared to placebo (HR, 1.59; 95\% CI 1.02, 2.46) over the 15 year follow-up period, indicating the need for safety precautions against excessive Se intake [60].

\subsection{Conclusions}

Se biofortification of edible plants has the potential to supply supra-adequate levels of $\mathrm{Se}$ in the human diet. Se biofortification also provides other minerals and vitamins resulting in potential nutritional advantages over Se supplementation alone. When evaluating the effects of Se biofortification on the nutritional quality of plants for human consumption, a comprehensive perspective needs to be considered in terms of minerals and antioxidants. In general, the use of selenate in hydroponics can yield plants with the highest levels of Se and increased antioxidant compounds without diminished plant biomass. However, recommendations for a biofortification technique that results in optimal content of other essential minerals relevant to human health are less conclusive. Among plant species, the effects on mineral content can differ with the same Se biofortification methods and similar Se treatment doses [10, 39] (Table 2). Because Se may negatively impact the uptake of some essential minerals such as: $\mathrm{Ca}, \mathrm{Mg}, \mathrm{K}, \mathrm{Fe}$, and $\mathrm{Cu}$ (Table 2), Se biofortification efforts should focus on plants that are not dietary staples to avoid imbalances in the intake of other minerals. Disease-preventative antioxidant compounds such as: phenols, anthocyanins, vitamin C, and flavonoids, increase with Se biofortification (Table 3). While glucosinolates decreased in mature plants, there were no changes in sprouts [55] (Table 3). Caution must be taken to avoid excessive consumption of Se; however, as Navarro-Alacaron and Cabrera-Vique [1] indicated, plants serve as effective buffers of excessive Se intake due to 
decreased yield at high levels of Se accumulation. However, choosing plants that are not dietary staples can also prevent potential for Se toxicity in humans. Selenate biofortification that can maximize Se, increase other essential minerals, and enhance antioxidant compounds in crops that are not dietary staples have the most potential as a functional food for disease prevention.

Finally, clinical trials are needed to fully assess the potential of Se-biofortified plants in human health. 


\subsection{References}

1. Navarro-Alarcon M, Cabrera-Vique C (2008) Selenium in food and the human body: A review. Sci Total Environ. 400(1-3):115-141.

2. Rayman MP (2008) Food-chain selenium and human health: emphasis on intake. Br J Nutr. $100(2): 254-268$.

3. Combs GF (2001) Selenium in global food systems. Br J Nutr. 85(5):517-547.

4. Stone CA, Kawai K, Kupka R, Fawzi WW (2010) Role of selenium in HIV infection. Nutr Rev 68(11):671-681.

5. Rayman MP (2012) Selenium and human health. Lancet 379(9822):1256-1268.

6. Zachara BA (2015) Selenium and selenium-dependent antioxidants in chronic kidney disease. Adv Clin Chem 68:131-151.

7. Terry N, Zayed AM, de Souza MP, Tarun AS (2000) Selenium in higher plants. Annu Rev Plant Physiol Plant Mol Biol. 51(1):401-432.

8. Puccinelli M, Malorgio F, Pezzarossa B (2017) Selenium enrichment of horticultural crops. Molecules. 22(6):933.

9. Hawrylak-Nowak B (2013) Comparative effects of selenite and selenate on growth and selenium accumulation in lettuce plants under hydroponic conditions. Plant Growth Regul. 70(2):149-157.

10. Saffaryazdi A, Lahouti M, Ganjeali A, Bayat H (2012) Impact of selenium supplementation on growth and selenium accumulation on spinach (Spinacia oleracea L.) plants. Not Sci Biol. 4(4):95-100.

11. He PP, Lv XZ, Wang GY (2004) Effects of Se and Zn supplementation on the antagonism against $\mathrm{Pb}$ and $\mathrm{Cd}$ in vegetables. Environ Int. 30(2):167-172. 
12. Boldrin PF, Faquin V, Ramos SJ, Boldrin KVF, Ávila FW, Guilherme LRG (2013) Soil and foliar application of selenium in rice biofortification. J Food Compos Anal. 31(2):238-244.

13. Malagoli M, Schiavon M, dall'Acqua S, Pilon-Smits EAH (2015) Effects of selenium biofortification on crop nutritional quality. Front Plant Sci. 6:280.

14. Wiesner-Reinhold M, Schreiner M, Baldermann S, et al (2017) Mechanisms of Selenium Enrichment and Measurement in Brassicaceous vegetables, and their application to human health. Front Plant Sci. 8:1365.

15. United States Department of Agriculture (2018). National Nutrient Database for Standard Reference 1 Release. USDA, Washington, D.C.

16. Vinceti M, Filippini T, Cilloni S, Bargellini A, Vergoni AV, Tsatsakis A, Ferrante M (2017) Health risk assessment of environmental selenium: emerging evidence and challenges. Mol Med Rep. 15(5):3323-3335

17. Boosalis MG (2008) The role of selenium in chronic disease. Nutr Clin Pract 23(2):152-160.

18. Vinceti M, Filippini T, Del Giovane C, et al (2018) Selenium for preventing cancer. Cochrane Database Syst Rev. 2018(1):CD005195.

19. Lippman SM, Klein EA, Goodman PJ, et al (2009) Effect of selenium and vitamin E on risk of prostate cancer and other cancers: The Selenium and Vitamin E Cancer Prevention Trial (SELECT). JAMA. 301(1):39-51.

20. Clark LC, Combs GF Jr, Turnbull BW, et al (1996) Effects of selenium supplementation for cancer prevention in patients with carcinoma of the skin. A randomized controlled trial. JAMA. 276(24):1957-1963. 
21. Gharipour M, Sadeghi M, Behmanesh M, Salehi M, Nezafati P, Gharpour A (2017) Selenium homeostasis and clustering of cardiovascular risk factors: A systematic review. Acta Biomed. 88(3):263-270.

22. Bekatorou A, Psarianos C, Koutinas AA (2006) Production of food grade yeasts. Food Technol Biotechol 44(3):407-415.

23. Abedi J, Saatloo MV, Nejati V, et al (2018) Selenium-enriched Saccharomyces cerevisiae reduces the progression of colorectal cancer. Biol Trace Elem Res. 185:424-432.

24. Ip C, Lisk DJ, Thompson HJ (1996) Selenium-enriched garlic inhibits the early stage but not the late stage of mammary carcinogenesis. Carcinogenesis. 17(9):1979-1982.

25. Ip C, Birringer M, Block E, Kotrebai M, Tyson JF, Uden PC, Lisk DJ (2000) Chemical speciation influences comparative activity of selenium-enriched garlic and yeast in mammary cancer prevention. J Agric Food Chem. 48(6):2062-2070. Erratum in: J Agric Food Chem 2000;48(9):4452.

26. Finley JW, Davis CD, Feng Y (2000) Selenium from high selenium broccoli protects rats from colon cancer. J Nutr. 130(9):2384-2389.

27. Davis CD, Zeng H, Finley JW (2002) Selenium-enriched broccoli decreases intestinal tumorigenesis in multiple intestinal neoplasia mice. J Nutr. 132(2):307-309.

28. Kryscio RJ, Abner EL, Caban-Holt A, et al (2017) Association of antioxidant supplement use and dementia in the prevention of Alzheimer's disease by vitamin E and selenium trial (PREADViSE). JAMA Neurol. 74(5):567-573.

29. Morris MC (2016) Nutrition and risk of dementia: overview and methodological issues. Ann N Y Acad Sci. 1367(1):31-37. 
30. Hu N, Yu JT, Tan L, Wang YL, Sun L, Tan L (2013) Nutrition and risk of Alzheimer's disease. Biomed Res Int. 2013:524820.

31. Zhang X, Liu C, Guo J, Song Y (2016) Selenium status and cardiovascular diseases: metaanalysis of prospective observational studies and randomized controlled trials. Eur J Clin Nutr 70:162-169

32. Ju W, Li X, Li Z, et al (2017) The effect of selenium supplementation on coronary heart disease: A systematic review and meta-analysis of randomized controlled trials. J Trace Elem Med Biol. 44:8-16.

33. Alfthan G, Eurola M, Ekholm P, et al (2015) Effects of nationwide addition of selenium to fertilizers on foods, and animal and human health in Finland: From deficiency to optimal selenium status in the population. J Trace Elem Med Biol. 31:142-147.

34. Saha U, Fayiga A, Sonon L (2017) Selenium in the soil-plant environment: A review. Int J Appl Agric Sci. 3:1-18.

35. Puccinelli M, Malorgio F, Rosellini I, Pezzarossa B (2017) Uptake and partitioning of selenium in basil (Ocimum basilicum L.) plants grown in hydroponics. Sci Hortic. 225:271276.

36. Ríos JJ, Rosales MA, Blasco B, Cervilla LM, Romero L, Ruiz JM (2008) Biofortification of Se and induction of the antioxidant capacity in lettuce plants. Sci Hortic. 116(3):248-255.

37. U.S. Department of Health and Human Services and U.S. Department of Agriculture. (2015) 2015 - 2020 Dietary Guidelines for Americans. Health.gov. https://health.gov/dietaryguidelines/2015/resources/2015-2020_Dietary_Guidelines.pdf. Accessed on January 7, 2018. 
38. Prentice A (2004) Diet, nutrition and the prevention of osteoporosis. Public Health Nutr. 7(1a):227-243.

39. Rios JJ, Blasco B, Leyva R, et al (2013) Nutritional balance changes in lettuce plant grown under different doses and forms of selenium. J Plant Nutr. 36(9):1344-1354.

40. Volpe SL (2013) Magnesium in disease prevention and overall health. Adv Nutr. 4(3):378S$383 \mathrm{~S}$.

41. Weaver CM (2013) Potassium and health. Adv Nutr 4(3):368S-377S.

42. Adrogué HJ, Madias NE (2014) The impact of sodium and potassium on hypertension risk. Semin Nephrol. 34(3):257-272.

43. White PJ, Broadley MR (2009) Biofortification of crops with seven mineral elements often lacking in human diets-iron, zinc, copper, calcium, magnesium, selenium, and iodine. New Phytol. 182(1):49-84.

44. Lobo V, Patil A, Phatak A, Chandra N (2010) Free radicals, antioxidants and functional foods: Impact on human health. Pharmacogn Rev. 4(8):118-126.

45. Pandey KB, Rizvi SI (2009) Plant polyphenols as dietary antioxidants in human health and disease. Oxid Med Cell Longev. 2(5):270-278.

46. Birben E, Sahiner UM, Sackesen C, Erzurum S, Kalayci O (2012) Oxidative stress and antioxidant defense. World Allergy Organ J. 5:9-19.

47. Zhu Z, Chen Y, Shi G, Zhang X (2017) Selenium delays tomato fruit ripening by inhibiting ethylene biosynthesis and enhancing the antioxidant defense system. Food Chem. 219:179184. 
48. Liu D, Li H, Wang Y, et al (2017) How exogenous selenium affects anthocyanin accumulation and biosynthesis-related gene expression in purple lettuce. Pol J Environ Stud. 26(2):717-722.

49. Hawrylak-Nowak B (2008) Enhanced selenium content in sweet basil (Ocimum basilicum) by foliar fertilization. Veg Crop Res Bul. 69:63-72.

50. Vinson JA, Hao Y, Su X, Zubik L (1998) Phenol antioxidant quantity and quality in foods: vegetables. J Agric Food Chem. 46(9):3630-3634.

51. Schiavon M, dall'Acqua S, Mietto A, et al (2013) Selenium fertilization alters the chemical composition and antioxidant constituents of tomato (Solanum lycopersicon L.). J Agric Food Chem. 61(44):10542-10554

52. Mahapatra DK, Asati V, Bharti SK (2015) Chalcones and their therapeutic targets for management of diabetes: Structural and pharmacological perspectives. Eur J Med Chem. 92:839-835.

53. Sánchez-Pujante PJ, Borja-Martínez M, Pedreño MÁ, Almagro L (2017) Biosynthesis and bioactivity of glucosinolates and their production in plant in vitro cultures. Planta 246(1):1932.

54. Barickman TC, Kopsell DA, Sams CE (2013) Selenium influences glucosinolate and isothiocyanates and increases sulfur uptake in Arabidopsis thaliana and rapid-cycling Brassica oleracea. J Agric Food Chem. 61(1):202-209.

55. Ávila FW, Faquin V, Yang Y, et al (2013) Assessment of the anticancer compounds Semethylselenocysteine and glucosinolates in Se-biofortified broccoli (Brassica oleracea L. var. italica) sprouts and florets. J Agric Food Chem. 61(26):6216-6223. 
56. Ávila FW, Yang Y, Faquin V, et al (2014) Impact of selenium supply on Semethylselenocysteine and glucosinolate accumulation in selenium-biofortified Brassica sprouts. Food Chem. 165:578-586.

57. Djujić IS, Jozanov-Stankov ON, Milovac M, Janković V, Djermanović V (2000) Bioavailability and possible benefits of wheat intake naturally enriched with selenium and its products. Biol Trace Elem Res. 77(3):273-285.

58. Wu J, Salisbury C, Graham R, Lyons G, Fenech M (2009) Increased consumption of wheat biofortified with selenium does not modify biomarkers of cancer risk, oxidative stress, or immune function in healthy Australian males. Environ Mol Mutagen 50(6):489-501.

59. Bermingham EN, Hesketh JE, Sinclair BR, Koolaard JP, Roy NC (2014) Selenium-enriched foods are more effective at increasing glutathione peroxidase (GPx) activity compared with selenomethionine: a meta-analysis. Nutrients. 6(10):4002-4031.

60. Rayman MP, Winther KH, Pastor-Barriuso R, et al (2018) Effect of long-term selenium supplementation on mortality: results from a multiple-dose, randomized control trial. Free Radic Biol Med. 127:46-54. 
Table 1. Selenium supplementation effects on human health.

\begin{tabular}{|c|c|c|c|c|}
\hline Study & Subjects & Se Dose & Results & Reference \\
\hline $\begin{array}{l}\text { meta-analysis } \\
\text { RCT }\end{array}$ & $\begin{array}{l}\mathrm{n}=27,232 \\
\text { men }+ \\
\text { women }\end{array}$ & $\begin{array}{l}200-400 \mu \mathrm{g} \cdot \mathrm{d}^{-1} \text { as enriched yeast, } \\
\text { L-selenomethionine }\end{array}$ & NS any cancer incidence; NS cancer mortality & Vinceti et al. [18] \\
\hline $\begin{array}{l}\text { SELECT } \\
\text { RCT }\end{array}$ & $\begin{array}{l}\mathrm{n}=35,533 \\
\text { men }\end{array}$ & $200 \mu \mathrm{g} \cdot \mathrm{d}^{-1}$ as L-selenomethionine & $\begin{array}{l}\text { NS prostate cancer incidence; NS any cancer } \\
\text { incidence; NS all-cause mortality }\end{array}$ & Lippman et al. [19] \\
\hline $\begin{array}{l}\text { NPCT } \\
\text { RCT }\end{array}$ & $\begin{array}{l}\mathrm{n}=1,312 \text { men } \\
+ \text { women }\end{array}$ & $200 \mu \mathrm{g} \cdot \mathrm{d}^{-1}$ as enriched yeast & $\begin{array}{l}\downarrow \text { lung, colorectal, prostate cancer incidence; } \downarrow \text { total } \\
\text { cancer incidence; } \downarrow \text { total cancer mortality }\end{array}$ & Clark et al. [20] \\
\hline $\begin{array}{l}\text { PREADViSE } \\
\text { SELECT ancillary RCT }\end{array}$ & $\mathrm{n}=7,338$ men & $200 \mu \mathrm{g} \cdot \mathrm{d}^{-1}$ as L-selenomethionine & NS dementia incidence & Krysico et al. [28] \\
\hline $\begin{array}{l}\text { meta-analysis } \\
\text { RCT }\end{array}$ & $\begin{array}{l}\mathrm{n}=36,511 \\
\text { men }+ \\
\text { women }\end{array}$ & $\begin{array}{l}75-300 \mu \mathrm{g} \cdot \mathrm{d}^{-1} \text { as enriched yeast, } \\
\text { L-selenomethionine, }\end{array}$ & NS CVD event incidence & Zhang et al. [31] \\
\hline $\begin{array}{l}\text { meta-analysis } \\
\text { RCT }\end{array}$ & $\begin{array}{l}\mathrm{n}=43,998 \\
\text { men }+ \\
\text { women }\end{array}$ & $\begin{array}{l}50 \text { to } 500 \mu \mathrm{g} \cdot \mathrm{d}^{-1} \text { as } \\
\text { L-selenomethionine, enriched } \\
\text { yeast, sodium selenite, brazil nut, } \\
\text { SelenoPrecise, Selenium amino } \\
\text { acid chelate, bound selenium }\end{array}$ & $\begin{array}{l}\text { Trend } \downarrow \text { CHD mortality; } \uparrow \text { GSH-Px; } \downarrow \text { serum CRP; NS } \\
\text { HDL/LDL level }\end{array}$ & Ju et al. [32] \\
\hline $\begin{array}{l}\text { meta-analysis } \\
\mathrm{RCT} \text {, cross-over }\end{array}$ & $\begin{array}{l}\mathrm{n}=304 \text { men }+ \\
\text { women }\end{array}$ & $\begin{array}{l}50 \text { to } 200 \mu \mathrm{g} \cdot \mathrm{d}^{-1} \text { as enriched yeast, } \\
\text { enriched milk, enriched onions, } \\
\text { enriched protein, onions }\end{array}$ & 个 GSH-Px & Bermingham et al. [59] \\
\hline
\end{tabular}

Abbreviations and symbols: NS, no significant difference; $\uparrow$ significant increase; $\downarrow$ significant decrease; RCT, randomized controlled trial; Se, selenium; CVD, cardiovascular disease; CHD, coronary heart disease; GSH-Px, glutathione peroxidase; CRP, C-reactive protein; HDL, high density lipoprotein; LDL, low density lipoprotein. 
Table 2. Effects of different methods of selenium biofortification on the mineral content in various plant species. All effects compared to respective study's control group.

\begin{tabular}{|c|c|c|c|c|c|c|c|c|c|c|}
\hline Plant Species & Se Dose & Se Content & $\mathrm{Ca}$ & $\mathrm{Mg}$ & $\mathrm{K}$ & $\mathrm{Mn}$ & $\mathrm{Zn}$ & $\mathrm{Fe}$ & $\mathrm{Cu}$ & Study \\
\hline $\begin{array}{l}\text { Brassica rapa } \\
\text { leaves }\end{array}$ & $\begin{array}{l}\text { Sodium selenite } \\
1.0 \mathrm{mg} \cdot \mathrm{kg}^{-1} \\
\text { Soil }\end{array}$ & $\begin{array}{c}0.30 \mathrm{mg} \cdot \mathrm{kg}^{-1} \mathrm{FW} \\
\left(3.75 \mathrm{mg} \cdot \mathrm{kg}^{-1} \mathrm{DW}\right)^{\mathrm{y}}\end{array}$ & $\uparrow$ & NS & - & $\uparrow$ & NS & $\downarrow$ & $\downarrow$ & He et al. [11] \\
\hline $\begin{array}{l}\text { Lactuca sativa } \\
\text { L. leaves }\end{array}$ & $\begin{array}{l}\text { Sodium selenite } \\
1.0 \mathrm{mg} \cdot \mathrm{kg}^{-1} \\
\text { Soil (pot) }\end{array}$ & $\begin{array}{c}0.31 \mathrm{mg} \cdot \mathrm{kg}^{-1} \mathrm{FW} \\
\left(6.20 \mathrm{mg} \cdot \mathrm{kg}^{-1} \mathrm{DW}\right)\end{array}$ & $\uparrow$ & NS & - & NS & NS & $\downarrow$ & $\downarrow$ & He et al. [11] \\
\hline $\begin{array}{l}\text { Lactuca sativa } \\
\text { L. leaves }\end{array}$ & $\begin{array}{l}\text { Sodium selenite } \\
75.0 \mathrm{mg} \cdot \mathrm{m}^{-2} \\
\text { Soil (field) }\end{array}$ & $\begin{array}{c}0.04 \mathrm{mg} \cdot \mathrm{kg}^{-1} \mathrm{FW} \\
\left(0.80 \mathrm{mg} \cdot \mathrm{kg}^{-1} \mathrm{DW}\right)\end{array}$ & $\uparrow$ & $\uparrow$ & - & NS & NS & $\uparrow$ & NS & He et al. [11] \\
\hline $\begin{array}{l}\text { Lactuca sativa } \\
\text { L. 'Philipus' } \\
\text { leaves }\end{array}$ & $\begin{array}{l}\text { Sodium selenate } \\
5.0-120.0 \mu \mathrm{M} \\
\text { Sodium selenite } \\
5.0-120.0 \mu \mathrm{M} \\
\text { Hydroponic } \\
\end{array}$ & $\begin{array}{l}\sim 2.0-43.0 \mathrm{mg} \cdot \mathrm{kg}^{-1} \mathrm{DW} \\
\sim 3.0-39.0 \mathrm{mg} \cdot \mathrm{kg}^{-1} \mathrm{DW}\end{array}$ & $\begin{array}{c}\downarrow \\
\downarrow \begin{array}{c}\downarrow 10.0-20.0 \mu \mathrm{M} \\
\uparrow 80.0 \mu \mathrm{M}\end{array}\end{array}$ & $\begin{array}{c}\downarrow 20.0,60.0- \\
120.0 \mu \mathrm{M} \\
\downarrow 10.0- \\
120.0 \mu \mathrm{M}\end{array}$ & NS & $\begin{array}{c}\uparrow 10.0 \mu \mathrm{M} \\
\qquad 5.0-10.0 \mu \mathrm{M} \\
\downarrow 120.0 \mu \mathrm{M}\end{array}$ & NS & $\begin{array}{c}\uparrow 10.0-20.0 \mu \mathrm{M} \\
\uparrow 60.0,120.0 \mu \mathrm{M} \\
\uparrow 20.0-40.0 \mu \mathrm{M} \\
\uparrow 80.0-120.0 \mu \mathrm{M}\end{array}$ & $\begin{array}{c}\downarrow 10.0,60.0 \\
120.0 \mu \mathrm{M} \\
\uparrow 20.0- \\
120.0 \mu \mathrm{M}\end{array}$ & Rios et al. [39] \\
\hline $\begin{array}{l}\text { Oryza sativa L. } \\
\text { 'BRSMG } \\
\text { Relâmpago' } \\
\text { grains }\end{array}$ & $\begin{array}{l}\text { Sodium selenate } \\
0.75 \mathrm{mg} \cdot \mathrm{kg}^{-1} \\
\text { Sodium selenite } \\
0.75 \mathrm{mg} \cdot \mathrm{kg}^{-1} \\
\text { Soil }\end{array}$ & $\begin{array}{l}\sim 6.40 \mathrm{mg} \cdot \mathrm{kg}^{-1} \mathrm{DW} \\
\sim 0.40 \mathrm{mg} \cdot \mathrm{kg}^{-1} \mathrm{DW}\end{array}$ & - & $\uparrow$ & - & $\uparrow$ & NS & $\begin{array}{l}\text { NS } \\
\text { NS }\end{array}$ & $\begin{array}{l}\text { NS } \\
\text { NS }\end{array}$ & Boldrin et al. [12] \\
\hline $\begin{array}{l}\text { Oryza sativa L. } \\
\text { 'BRSMG } \\
\text { Relâmpago' } \\
\text { grains }\end{array}$ & $\begin{array}{l}\text { Sodium selenate } \\
50.0 \mu \mathrm{M} \\
\text { Sodium selenite } \\
50.0 \mu \mathrm{M} \\
\text { Foliar }\end{array}$ & $\begin{array}{l}\sim 1.20 \mathrm{mg} \cdot \mathrm{kg}^{-1} \mathrm{DW} \\
\sim 0.25 \mathrm{mg} \cdot \mathrm{kg}^{-1} \mathrm{DW}\end{array}$ & - & NS & - & NS & NS & $\begin{array}{l}\uparrow \\
\text { NS }\end{array}$ & $\begin{array}{l}\text { NS } \\
\downarrow\end{array}$ & Boldrin et al. [12] \\
\hline $\begin{array}{l}\text { Spinacia } \\
\text { oleracea L. } \\
\text { 'Missouri' } \\
\text { leaves }\end{array}$ & $\begin{array}{l}\text { Sodium selenite } \\
12.7 \mu \mathrm{M} \\
25.3 \mu \mathrm{M} \\
50.7 \mu \mathrm{M} \\
76.0 \mu \mathrm{M} \\
126.6 \mu \mathrm{M} \\
\text { Hydroponic }\end{array}$ & $\begin{array}{l}1710 \mathrm{mg} \cdot \mathrm{kg}^{-1} \mathrm{DW} \\
2050 \mathrm{mg} \cdot \mathrm{kg}^{-1} \mathrm{DW} \\
2840 \mathrm{mg} \cdot \mathrm{kg}^{-1} \mathrm{DW} \\
3830 \mathrm{mg} \cdot \mathrm{kg}^{-1} \mathrm{DW} \\
3890 \mathrm{mg} \cdot \mathrm{kg}^{-1} \mathrm{DW}\end{array}$ & $\begin{array}{l}\uparrow \\
\uparrow \\
\uparrow \\
\text { NS } \\
\text { NS }\end{array}$ & $\begin{array}{l}- \\
- \\
- \\
- \\
-\end{array}$ & $\begin{array}{l}\text { NS } \\
\text { NS } \\
\text { NS } \\
\downarrow \\
\downarrow\end{array}$ & $\begin{array}{l}- \\
- \\
- \\
- \\
-\end{array}$ & $\begin{array}{l}- \\
- \\
- \\
- \\
-\end{array}$ & $\begin{array}{l}- \\
- \\
- \\
- \\
-\end{array}$ & $\begin{array}{l}- \\
- \\
- \\
- \\
-\end{array}$ & Saffaryazdi et al. [10] \\
\hline
\end{tabular}

y Values in parentheses indicate calculated DW values based on 95\% water content of lettuce and 92\% water content of cabbage from USDA [15].

Abbreviations and symbols: NS, no significant difference; $\uparrow$ significant increase; $\downarrow$ significant decrease; $\sim$, approximate value based on figure; DW, dry weight; FW, fresh weight; Se, selenium; Ca, calcium; Mg, magnesium; K, potassium; Mn, manganese; $\mathrm{Zn}$, zinc; $\mathrm{Fe}$, iron; $\mathrm{Cu}$, copper. 
Table 3. Effects of different methods of selenium biofortification on antioxidant compound content in various plant species. All effects compared to respective study's control group.

\begin{tabular}{|c|c|c|c|c|c|c|c|c|}
\hline Plant Species & Se Dose & Se Content & TPC & Anth & AA & Flav & GS & Study \\
\hline \multirow[t]{5}{*}{ Lactuca sativa L. 'Philipus' leaves } & Sodium selenate & & & & & & & Rios et al. [36] \\
\hline & $5.0-120.0 \mu \mathrm{M}$ & $\sim 2.0-43.0 \mathrm{mg} \cdot \mathrm{kg}^{-1} \mathrm{DW}$ & $\uparrow 5.0-$ & - & $\uparrow 5.0-$ & $\uparrow 5.0-$ & - & \\
\hline & Sodium selenite & & $120.0 \mu \mathrm{M}$ & & $120.0 \mu \mathrm{M}$ & $120.0 \mu \mathrm{M}$ & & \\
\hline & $5.0-120.0 \mu \mathrm{M}$ & $\sim 3.0-39.0 \mathrm{mg} \cdot \mathrm{kg}^{-1} \mathrm{DW}$ & $\uparrow 5.0-$ & - & $\uparrow 5.0-$ & $\uparrow 5.0-$ & - & \\
\hline & Hydroponic & & $120.0 \mu \mathrm{M}$ & & $120.0 \mu \mathrm{M}$ & $120.0 \mu \mathrm{M}$ & & \\
\hline \multirow{6}{*}{$\begin{array}{l}\text { Lactuca sativa L. 'Purple Rome' } \\
\text { leaves }\end{array}$} & Sodium selenite & & & & & & & Liu et al. [48] \\
\hline & $4.0 \mu \mathrm{M}$ & $\sim 0.006 \mathrm{mg} \cdot \mathrm{kg}^{-1} \mathrm{FW}\left(0.12 \mathrm{mg} \cdot \mathrm{kg}^{-1} \mathrm{DW}\right)^{\mathrm{y}}$ & - & $\uparrow$ & - & - & - & \\
\hline & $8.0 \mu \mathrm{M}$ & $\sim 0.014 \mathrm{mg} \cdot \mathrm{kg}^{-1} \mathrm{FW}\left(0.28 \mathrm{mg} \cdot \mathrm{kg}^{-1} \mathrm{DW}\right)$ & - & $\uparrow$ & - & - & - & \\
\hline & $12.0 \mu \mathrm{M}$ & $\sim 0.019 \mathrm{mg} \cdot \mathrm{kg}^{-1} \mathrm{FW}\left(0.38 \mathrm{mg} \cdot \mathrm{kg}^{-1} \mathrm{DW}\right)$ & - & NS & - & - & - & \\
\hline & $16.0 \mu \mathrm{M}$ & $\sim 0.025 \mathrm{mg} \cdot \mathrm{kg}^{-1} \mathrm{FW}\left(0.50 \mathrm{mg} \cdot \mathrm{kg}^{-1} \mathrm{DW}\right)$ & - & $\downarrow$ & - & - & - & \\
\hline & Hydroponic & & & & & & & \\
\hline \multirow{8}{*}{$\begin{array}{l}\text { Ocimum basilicum } \mathrm{L} \text {. } \\
\text { leaves }\end{array}$} & Sodium selenate & & & & & & & Hawrylak-Nowak [49] \\
\hline & $12.7 \mu \mathrm{M}$ & $\sim 1.0 \mathrm{mg} \cdot \mathrm{kg}^{-1} \mathrm{DW}$ & NS & NS & - & - & - & \\
\hline & $38.0 \mu \mathrm{M}$ & $\sim 4.5 \mathrm{mg} \cdot \mathrm{kg}^{-1} \mathrm{DW}$ & $\uparrow$ & NS & - & - & - & \\
\hline & $63.3 \mu \mathrm{M}$ & $\sim 15.0 \mathrm{mg} \cdot \mathrm{kg}^{-1} \mathrm{DW}$ & $\uparrow$ & NS & - & - & - & \\
\hline & $126.6 \mu \mathrm{M}$ & $\sim 15.0 \mathrm{mg} \cdot \mathrm{kg}^{-1} \mathrm{DW}$ & $\uparrow$ & $\uparrow$ & - & - & - & \\
\hline & $253.3 \mu \mathrm{M}$ & $\sim 37.0 \mathrm{mg} \cdot \mathrm{kg}^{-1} \mathrm{DW}$ & $\uparrow$ & $\uparrow$ & - & - & - & \\
\hline & $633.2 \mu \mathrm{M}$ & $\sim 150.0 \mathrm{mg} \cdot \mathrm{kg}^{-1} \mathrm{DW}$ & NS & $\uparrow$ & - & - & - & \\
\hline & Foliar & & & & & & & \\
\hline \multirow{3}{*}{$\begin{array}{l}\text { Solanum lycopersicon 'Provence' } \\
\text { fruit }^{z}\end{array}$} & Sodium selenate & & & & & & & Zhu et al. [47] \\
\hline & $12.7 \mu \mathrm{M}$ & $\mathrm{N} / \mathrm{A}$ & - & - & $\uparrow$ & - & - & \\
\hline & Foliar & & & & & & & \\
\hline \multirow{7}{*}{$\begin{array}{l}\text { Spinacia oleracea L. 'Missouri' } \\
\text { leaves }\end{array}$} & Sodium selenite & & & & & & & Saffaryazdi et al. [10] \\
\hline & $12.7 \mu \mathrm{M}$ & $1710 \mathrm{mg} \cdot \mathrm{kg}^{-1} \mathrm{DW}$ & NS & - & - & - & - & \\
\hline & $25.3 \mu \mathrm{M}$ & $2050 \mathrm{mg} \cdot \mathrm{kg}^{-1} \mathrm{DW}$ & NS & - & - & - & - & \\
\hline & $50.7 \mu \mathrm{M}$ & $2840 \mathrm{mg} \cdot \mathrm{kg}^{-1} \mathrm{DW}$ & $\uparrow$ & - & - & - & - & \\
\hline & $76.0 \mu \mathrm{M}$ & $3830 \mathrm{mg} \cdot \mathrm{kg}^{-1} \mathrm{DW}$ & $\uparrow$ & - & - & - & - & \\
\hline & $126.6 \mu \mathrm{M}$ & $3890 \mathrm{mg} \cdot \mathrm{kg}^{-1} \mathrm{DW}$ & $\uparrow$ & - & - & - & - & \\
\hline & Hydroponic & & & & & & & \\
\hline \multirow[t]{3}{*}{ Brassica oleracea leaves } & Sodium selenate & & & & & & & Barickman et al. [54] \\
\hline & $5.1-40.5 \mu \mathrm{M}$ & $200-2050 \mathrm{mg} \cdot \mathrm{kg}^{-1} \mathrm{DW}$ & - & - & - & - & $\downarrow$ & \\
\hline & Hydroponic & & & & & & & \\
\hline
\end{tabular}




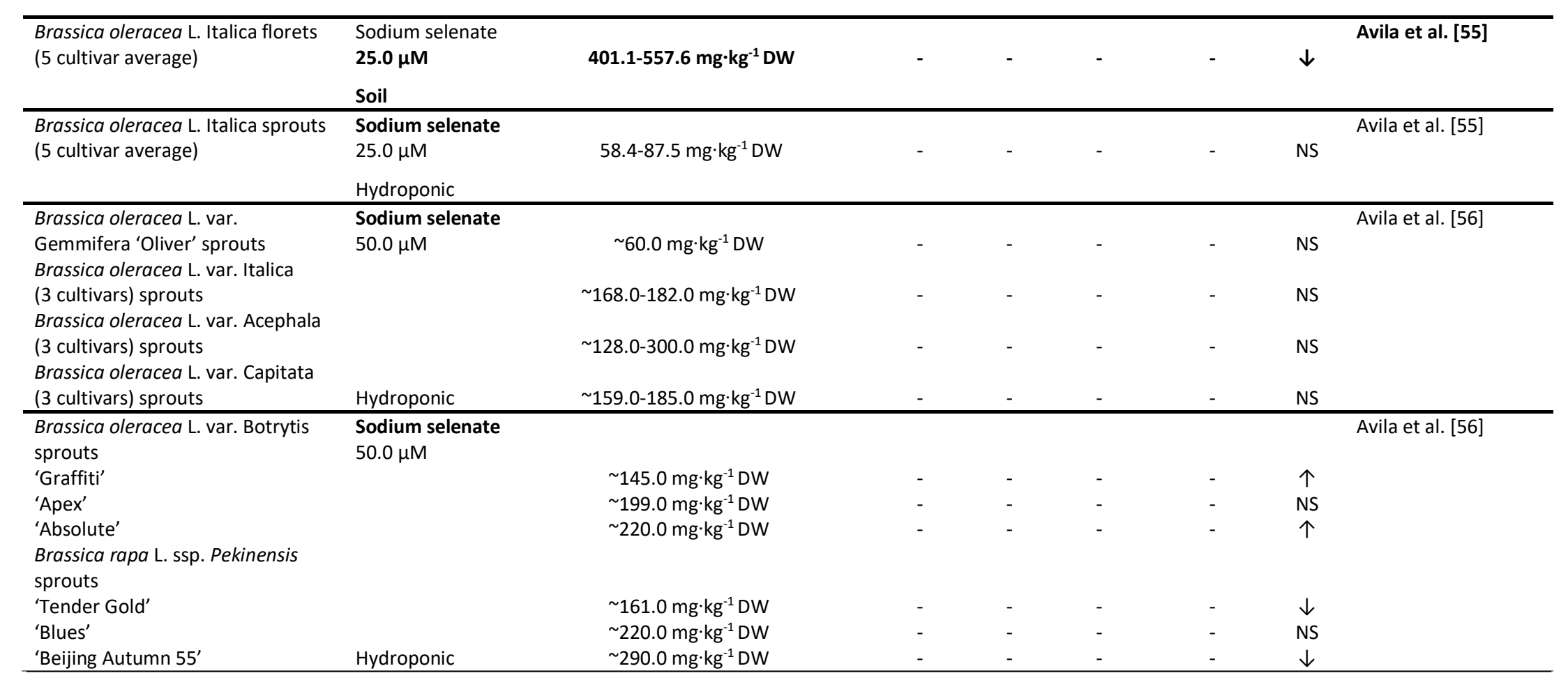

y Values in parentheses indicate calculated DW values based on 95\% water content of lettuce from USDA [15].

${ }^{2}$ Fruit at day 0.

Abbreviations and symbols: NS, no significant difference; $\uparrow$ significant increase; $\downarrow$ significant decrease; $\sim$, approximate value based on figure; DW, dry weight;

FW, fresh weight; Se, selenium; TPC, total phenolic content; Anth, anthocyanins; AA, ascorbic acid; Flav, flavonoids; GS, total glucosinolates. 


\subsection{Chapter 1:}

The Effect of Sodium Selenate Biofortification on Plant Yield, Mineral Content, and

\section{Antioxidant Capacity of Culinary Herb Microgreens}

Rachel Newman ${ }^{1}$, Youyoun Moon ${ }^{2}$, Carl Sams ${ }^{3}$, Janet Tou ${ }^{1}$, Nicole Waterland ${ }^{2}$

${ }^{1}$ Division of Animal and Nutritional Sciences, West Virginia University

${ }^{2}$ Division of Plant and Soil Sciences, West Virginia University

${ }^{3}$ Plant Sciences Department, The University of Tennessee

Corresponding Author:

Dr. Nicole Waterland

Division of Plant and Soil Sciences

West Virginia University

Morgantown, WV 26506

Tel: (304)293-2969

e-mail:nlwaterland@mail.wvu.edu 


\subsection{Introduction}

Selenium (Se) is an essential trace mineral and a component of human selenoproteins, including some endogenous antioxidant enzymes [1]. While Se deficiency is uncommon in North America, it is estimated that one billion people worldwide are Se-deficient, contributing to a cardiomyopathy known as Keshan Disease [2]. Further, studies have suggested that supraadequate levels of Se intake may be beneficial in the prevention of chronic diseases including cancer and cardiovascular disease [3]. Plants are a major dietary source of Se, but the amount in plants is dependent on soil Se content [1]. The process of enhancing plant nutrient content during their growth using biofortification has been considered as a solution to worldwide mineral deficiencies and for chronic disease prevention [4]. In general, sodium selenate is considered more efficient for increasing Se content of plants compared to sodium selenite, due to its improved translocation to the shoots of plants, whereas selenite accumulates in the roots in lower quantities [5,6]. Addition of sodium selenate to hydroponic nutrient solutions has been utilized as an efficient method of biofortification, as hydroponic growing conditions allow for a highlycontrolled addition of Se to the plants [7].

Different plant species exhibit varying levels of Se tolerance instead of essentiality, which is evident through decreasing crop yields as the amount of Se supplied increases [6]. Thus, a goal of Se biofortification has been to increase Se content while avoiding significant decreases in crop yield [7]. However, several studies have reported that Se biofortification can impact other dietary minerals as well as plant antioxidant compounds, such as polyphenols, which have anticancer and cardioprotective properties [8-12]. Therefore, it is imperative that studies evaluating the effects of Se biofortification include not only the content of Se but content of other nutrients important to human health. 
Culinary herbs can be added to meals for flavoring in place of salt or fat and can increase consumer acceptability of vegetable consumption [13-15]. Popular culinary herbs such as basil (Ocimum basilicum), cilantro (Coriandrum sativum), and scallions (Allium fistulosum) present an opportunity for Se biofortification as small additions to flavor meals resulting in increased $\mathrm{Se}$ intake without potential for toxicity. Plants grown to microgreen stage are becoming increasingly popular among consumers for their nutritional quality and distinctive flavors [16]. Microgreens are generally defined as plants grown to the first set of true leaves and typically range in height from 2.5 to $7.5 \mathrm{~cm}$ [16], making them a quick and easy crop to biofortify. Yet, studies on $\mathrm{Se}$ biofortification of microgreens are lacking in the scientific literature. The objective of this study was to investigate the effect of increasing levels of Se biofortification of three species of culinary herbs grown to microgreen stage in hydroponic conditions on plant yield, total Se content as well as content of several other minerals essential to human health, and antioxidant phytochemicals. The study tests the hypothesis that biofortification of culinary herb microgreens increases the content of Se, other minerals important to human health, and antioxidants. Enhancements in nutrient profiles would enable these herbs to serve as a functional food for improving human nutritional status and health.

\subsection{Materials and Methods}

\subsubsection{Plant Growth and Harvest}

Seeds of Ocimum basilicum, Coriandrum sativum, and Allium fistulosum were purchased from Johnny's Selected Seeds (Winslow, ME). Seeds were sown in $25.4 \times 25.4 \times 2.54 \mathrm{~cm}$ black growing trays onto Biostrate felt mats $(0.35 \mathrm{~cm}$ thickness; Grow-Tech, South Portland, MA). Seed density per tray for each species were as follows: 2.8 seeds $\mathrm{cm}^{-2}$ (3.01 g or 1806 seeds) of basil seeds, 2.8 seeds $\cdot \mathrm{cm}^{-2}$ (21.67 g or 1805 seeds) of cilantro seeds, and 3.4 seeds $\cdot \mathrm{cm}^{-2}(4.86 \mathrm{~g}$ 
or 2203 seeds) of scallion seeds. Treatments for all species consisted of $1 / 2$ concentrated Hoagland's modified nutrient solution (PhytoTechnology Lab., Shawnee Mission, KS) prepared in ultrapure water $(18.2 \mathrm{M} \Omega-\mathrm{cm})$ and supplemented with sodium selenate $\left(\mathrm{Na}_{2} \mathrm{SeO}_{4}\right)$ in concentrations of 0.0 (control), 2.5 , and $5.0 \mathrm{mg} \cdot \mathrm{L}^{-1}$ of Se. Scallions received an additional treatment with $10.0 \mathrm{mg} \cdot \mathrm{L}^{-1}$ of Se as a member of the Allium family, which is known for their potential to accumulate Se in levels up to $1000 \mu \mathrm{g} \cdot \mathrm{g}^{-1}$ dry weight (DW) without toxic effects[1,17]. Treatment levels were determined based on literature search and preliminary trials with doses that maximized Se content without detrimental effects on plant growth.

Basil and cilantro treatments were completed in three replicates. Based on preliminary studies with low yields, scallions were grown in three replicates with double trays, which were combined to obtain enough sample for the various analyses. Each tray received an initial $180 \mathrm{~mL}$ of $1 / 2$ concentrated Hoagland's nutrient solution. Trays were placed into growth chambers (Percival Scientific, Perry, IA) with a photoperiod of 16/8 h light/dark, temperatures of 19.7/18.7 $\pm 1.0 / 0.8{ }^{\circ} \mathrm{C}$ day/night, relative humidity of $57.3 \pm 0.8 \%$, and photosynthetic photon flux density of $210 \pm 7.9 \mu \mathrm{mol} \cdot \mathrm{m}^{-2} \cdot \mathrm{s}^{-1}$ (mean $\pm \mathrm{SD}$ ). $\mathrm{pH}$ of all nutrient solutions averaged $5.4 \pm 0.1$. Plants were watered with ultrapure water as needed to avoid drying of seeds during germination. Treatments began when the seeds for each species were $80 \%$ germinated. Plants were fertigated as needed by adding solutions directly to the growing mats based on saturation of the mats within plant species. Each tray within plant species received the same daily volume of treatment. Total volume of treatment per tray for each species over the 25-day treatment period was 2965, 2835, and $3825 \mathrm{~mL}$ for basil, scallions, and cilantro, respectively.

Each plant species was harvested after 25 days of treatment, at which point basil and cilantro had two true leaves and scallions had one true leaf. Microgreens were harvested at the 
base, approximately $1.0 \mathrm{~cm}$ from the growing pad. Any seed coats that were still attached were removed, and fresh weight per tray was recorded without seed coats. Microgreens were immediately flash frozen with liquid nitrogen and stored at $-80^{\circ} \mathrm{C}$ until freeze-dried (Virtus Genesis 35 SQ Super XL, SP Industries, Gardiner, NY). Dried samples were weighed and ground into a fine powder with mortar and pestle. Samples were then stored in $-80{ }^{\circ} \mathrm{C}$ until further analysis. Water content was determined for each tray by comparing DW to fresh weight (FW). All measured parameters were converted to FW basis, as microgreens are consumed exclusively fresh.

\subsubsection{Mineral Analysis}

Measurement of minerals were according to Barickman et al [18]. Briefly, $0.5 \mathrm{~g}$ of lyophilized ground plant tissue was combined with $10 \mathrm{~mL}$ of $70 \% \mathrm{HNO}_{3}$ and digested in a microwave digestion system (Ethos model, Milestone Inc., Shelton, CT, USA). Digestion procedures for organically based matrices were followed [19]. Digestions were diluted with 2\% $\mathrm{HNO}_{3} / 0.5 \% \mathrm{HCl}(\mathrm{v} / \mathrm{v})$. The sample was measured for Se, sulfur $(\mathrm{S})$, sodium $(\mathrm{Na})$, potassium $(\mathrm{K})$, phosphorus $(\mathrm{P})$, calcium $(\mathrm{Ca})$, magnesium $(\mathrm{Mg})$, copper $(\mathrm{Cu})$, iron $(\mathrm{Fe})$, manganese $(\mathrm{Mn})$, zinc

(Zn) and boron (B) by inductively coupled plasma mass spectrometry (ICP-MS) using an Agilent 7500ce ICP-MS system (Agilent Technologies, Inc., Wilmington, DE, USA) equipped with an ASX-510 (CETAC, Omaha, NE, USA) autosampler. Water content percentages were used to convert and express mineral content on FW basis.

\subsubsection{Determination of Total Phenolic Content}

Total phenolics were extracted using the method of Nicolle et al. [20] with modifications. $10 \mathrm{mg}$ of freeze-dried microgreen powder was extracted with $1 \mathrm{~mL}$ of methanol-water mixture $(60: 40, v / v)$, vortexed for 10 seconds, and centrifuged at $16,110 \mathrm{~g}$ for 20 minutes at $4{ }^{\circ} \mathrm{C}$. The 
supernatant was collected, and the sample was re-extracted with another $1 \mathrm{~mL}$ of the methanolwater mixture. Supernatants were combined and stored in $-80^{\circ} \mathrm{C}$ until analysis.

Total phenolic content was determined according to Waterland et al. [21] with modifications for a 96-well microplate reader. Briefly, $18.2 \mu \mathrm{L}$ of sample extract or gallic acid standard $\left(0,10,20,50,100,150,200,250\right.$, and $\left.300 \mathrm{mg} \cdot \mathrm{L}^{-1}\right)$ was plated in duplicates, followed by $90.9 \mu \mathrm{L}$ of $0.5 \mathrm{~N}$ Folin-Ciocalteau reagent (Sigma-Aldrich, St. Louis, MO). The plate was incubated for 5 minutes, then $90.9 \mu \mathrm{L}$ of $0.5 \mathrm{M}$ sodium carbonate was added to each cell and mixed. The plate incubated at room temperature in the dark for one hour. Absorbance was measured at $765 \mathrm{~nm}$ with a BioTek Synergy H1 microplate reader (Winooski, VT). Inter-assay coefficient of variation was $5.7 \%$. Total phenolic content was determined using the gallic acid standard curve and expressed in mg of gallic acid equivalents (GAE) per gram. Water content percentages were used to convert and express total phenolics on FW basis.

\subsubsection{Oxygen Radical Absorbance Capacity (ORAC) Assay}

Sample preparation for the hydrophilic assay was completed according to the procedure by Ou et al [22]. Briefly, $10 \mathrm{mg}$ of freeze-dried microgreen powder was added to a microcentrifuge tube with $0.4 \mathrm{~mL}$ of acetone-water mixture $(50: 50, \mathrm{v} / \mathrm{v})$, and vortexed at room temperature for 1 hour. The tube was then centrifuged at $16,110 \mathrm{~g}$ for 15 minutes at $4^{\circ} \mathrm{C}$, and the supernatant was collected in a separate clean tube and stored in $-20^{\circ} \mathrm{C}$ until assayed.

Sample preparation for the lipophilic assay was completed according to OxiSelect ORAC Activity Assay kit protocol (CellBio Labs, San Diego, CA). Briefly, $10 \mathrm{mg}$ of freeze-dried microgreen powder was added to a microcentrifuge tube with $0.4 \mathrm{~mL}$ of pure acetone, and vortexed at room temperature for 1 hour. The tube was stored in $-20{ }^{\circ} \mathrm{C}$ until the assay was started, which allowed fiber to separate from the acetone extract. 
Hydrophilic and lipophilic ORAC assays were completed using OxiSelect ORAC Activity Assay kit protocol (CellBio Labs, San Diego, CA). Fluorescence was read using a Biotek Synergy H1 (Winooski, VT) microplate reader. Inter-assay coefficient of variation was 21.0\%. Calculations were completed according to CellBio Labs protocol, using 0, 5, 10, 20, 40, 50 , and $75 \mu \mathrm{M}$ of Trolox for both lipophilic and hydrophilic standard curves, and results were expressed in $\mu$ mol Trolox equivalents (TE) per gram. Lipophilic and hydrophilic portions were summed to equal total ORAC values. Water content percentages were used to convert and express ORAC values on FW basis.

\subsubsection{Statistical Analysis}

Statistical analyses were performed by JMP version 13 (SAS Institute Inc., Cary, NC). One-way analysis of variance (ANOVA) was used to determine differences among treatment groups for each herb species. Post hoc multiple comparison tests were performed using Tukey's test with significance at $p<0.05$.

\subsection{Results and Discussion}

\subsubsection{Selenium Content}

Se content increased $(p<0.05)$ with increasing Se treatments for all three culinary herbs

(Figure 1). Se content of scallions increased by 98, 202, and 507 times for doses of 2.5, 5.0, and $10.0 \mathrm{mg} \cdot \mathrm{L}^{-1} \mathrm{Se}$, respectively, compared to control (Figure 1A). Dry weight values for scallions were $824.9,1530.4$, and $2481.4 \mu \mathrm{g} \cdot \mathrm{g}^{-1} \mathrm{Se}$ for $2.5,5.0,10.0 \mathrm{mg} \cdot \mathrm{L}^{-1}$ Se treatments, respectively (Figure 1B). These values confirm Allium's role as an accumulator of Se and indicate hyperaccumulator status by accumulating Se to levels higher than $1000 \mu \mathrm{g} \cdot \mathrm{g}^{-1} \mathrm{DW}$ [4]. For basil, Se content increased by 64 and 155 times at doses of 2.5 and $5.0 \mathrm{mg} \cdot \mathrm{L}^{-1} \mathrm{Se}$ compared to control (Figure 1A). On a dry weight basis, basil accumulated 338.6 and $690.0 \mu \mathrm{g} \cdot \mathrm{g}^{-1}$ Se at doses of 2.5 
and $5.0 \mathrm{mg} \cdot \mathrm{L}^{-1} \mathrm{Se}$, respectively (Figure 1B). Gupta and Gupta [4] define secondary accumulators as plant species that are capable of accumulating Se up to 100 to $1000 \mu \mathrm{g} \cdot \mathrm{g}^{-1} \mathrm{DW}$. Based on this definition, these values are high enough to classify basil as a secondary accumulator of Se. In the current study, total Se uptake in basil plants was higher compared to the study by Kopsell et al. [23], which utilized foliar application of Se at $32.0 \mathrm{mg} \cdot \mathrm{L}^{-1}$, yielding basil plants with 22.9 to 55.7 $\mu \mathrm{g} \cdot \mathrm{g}^{-1} \mathrm{Se}$ DW in leaf tissues. Puccinelli et al. [24] demonstrated an accumulation of approximately $175 \mu \mathrm{g} \cdot \mathrm{g}^{-1} \mathrm{DW}$ Se in basil leaves at 27 days of treatment with $12.0 \mathrm{mg} \cdot \mathrm{L}^{-1} \mathrm{Se}$ in hydroponic conditions. These results suggest the efficiency of utilizing hydroponic conditions for Se biofortification of basil plants.

Few studies have assessed Se biofortification of cilantro. In our study, Se content of cilantro increased by 18 and 40 times at 2.5 and $5.0 \mathrm{mg} \cdot \mathrm{L}^{-1} \mathrm{Se}$ treatments compared to control (Figure 1A). Dry weight values for cilantro included 136.2 and $287.2 \mu \mathrm{g} \cdot \mathrm{g}^{-1} \mathrm{Se}$ at doses of 2.5 and $5.0 \mathrm{mg} \cdot \mathrm{L}^{-1} \mathrm{Se}$, respectively (Figure $1 \mathrm{~B}$ ). This also places cilantro into the category of a secondary Se accumulator. Kopsell et al. [23], using foliar Se application of cilantro at 32.0 $\mathrm{mg} \cdot \mathrm{L}^{-1} \mathrm{Se}$, yielded cilantro plants with 9.3 to $49.5 \mu \mathrm{g} \cdot \mathrm{g}^{-1} \mathrm{Se}$ DW. Lower Se content compared to our study also support the improved efficiency of Se uptake using hydroponic conditions for cilantro. Additionally, the high content of Se in herbs in this study may be a result of a general high mineral uptake for these plants within 25 days after germination. Microgreens in this study were supplied with fresh nutrient solutions daily, and therefore, a constant supply of Se was available. The smaller biomass of herb microgreens can also cause Se content to be concentrated. A "dilution effect" of minerals has been observed as basil plants mature and biomass increases [24]. It is also noteworthy that despite requiring the lowest amount of treatment volume (2835 
$\mathrm{mL}$ ), scallions accumulated the highest content of Se at 2.5 and $5.0 \mathrm{mg} \cdot \mathrm{L}^{-1}$ Se treatments compared to basil and cilantro, which required 2965 and $3825 \mathrm{~mL}$ of treatment, respectively.

\subsubsection{Plant Yield}

At high Se doses, growth stunting is a common symptom of Se toxicity in plants [6]. Chemically similar, Se and S undergo a similar assimilation pathway in plants; therefore, substitution of S-amino acids with Se-amino acids (cysteine and methionine with selenocysteine and selenomethionine, respectively) in proteins can cause detrimental changes in the protein's tertiary structure resulting in plant Se toxicity $[4,25]$. In the current study, scallion yield decreased $(68.0 \%)$ at $10.0 \mathrm{mg} \cdot \mathrm{L}^{-1} \mathrm{Se}$, while basil yield decreased $(35.5 \%)$ at the $5.0 \mathrm{mg} \cdot \mathrm{L}^{-1} \mathrm{Se}$ treatment (Figure 2A-B). It has been suggested that Alliums can limit the amount of Se incorporated into proteins, protecting the plant against toxicity [25]. Interestingly, cilantro's yield was not affected by Se treatments used in this study (Figure 2C). To our knowledge, no studies of cilantro Se biofortification have reported plant yield. In a study using carrots, a member of the Apiaceae family along with cilantro, sodium selenate biofortification yielded carrot leaves with an average Se content of approximately $52.0 \mu \mathrm{g} \cdot \mathrm{g}^{-1} \mathrm{DW}$ with no significant effect on yield [26]. However, there was a negative relationship $(r=-0.53)$ between Se and $\mathrm{S}$ content in carrot leaves [26]. Se and S use the same root transporters and therefore, selenate and sulfate compete for uptake in plants [6]. Despite the decrease in S, there was no effect on plant biomass, possibly due to a decreased $\mathrm{S}$ need in carrots [26].

In our study, $\mathrm{S}$ content of cilantro decreased with increasing Se treatments, but the effect was not significant ( $p=0.1027$ ) (Figure 3). A study by Rios et al. [27] showed S content of lettuce was not affected by Se biofortification at doses of 0.40 to $1.6 \mathrm{mg} \cdot \mathrm{L}^{-1} \mathrm{Se}$ as selenate. Further, Rios et al. [27] demonstrated a decrease of S content in lettuce from 4.7 to $9.5 \mathrm{mg} \cdot \mathrm{L}^{-1} \mathrm{Se}$ 
treatments after a maximum increase at $3.2 \mathrm{mg} \cdot \mathrm{L}^{-1} \mathrm{Se}$, suggesting an antagonistic relationship between Se and $\mathrm{S}$ at these higher concentrations. The relationship between Se and $\mathrm{S}$ uptake varies among plant species [17]. In the current study, S content increased with increasing Se treatment for scallions and basil. In scallions, S content increased significantly by $124.5 \%$, $140.8 \%$ and $228.6 \%$ at doses of $2.5,5.0$, and $10.0 \mathrm{mg} \cdot \mathrm{L}^{-1} \mathrm{Se}$, respectively (Figure 3). Basil S content increased significantly by $46.4 \%$ and $96.4 \%$ at doses of 2.5 and $5.0 \mathrm{mg} \cdot \mathrm{L}^{-1} \mathrm{Se}$, respectively (Figure 3). Previous studies have also reported increases in S content with high levels of selenate biofortification $[27,28]$. In humans, organic S can be used to increase synthesis of glutathione (GSH), the most abundant endogenous non-protein thiol, which has a protective role against free radical damage as well as potential to enhance immune function [29]. Vegans are a group at risk for subclinical S deficiency [29] and may benefit from increased dietary S.

Collectively, results showed that of the three culinary herbs investigated in the current study, scallion microgreens at $5.0 \mathrm{mg} \cdot \mathrm{L}^{-1}$ Se treatment level have the potential to supply the highest levels of Se to the diet without causing significant loss of plant biomass. However, in addition to supplying high Se without reducing plant growth, successful Se biofortification should also provide adequate minerals for animal and human nutrition.

\subsubsection{Other Dietary Minerals}

Se added in the form of sodium selenate to the nutrient solution significantly increased Na content in herbs except for basil ( $p=0.0531$ ) (Table 1). Despite the increases, the highest amount of $\mathrm{Na}$ accumulation observed in this study was $0.053 \mathrm{mg} \cdot \mathrm{g}^{-1} \mathrm{FW}$ for $10.0 \mathrm{mg} \cdot \mathrm{L}^{-1} \mathrm{Se}$ scallions (Table 1). This translates to about $1.0 \mathrm{mg}$ of $\mathrm{Na}$ for $20 \mathrm{~g}$ of fresh scallion microgreens. The most recent Dietary Guidelines for Americans [30] recommends restricting Na consumption to less than 2,300 $\mathrm{mg}$ per day; thus, the amount of $\mathrm{Na}$ coming from this large amount of fresh 
scallion microgreens is negligible. Excessive $\mathrm{Na}$ intake in the human diet combined with inadequate $\mathrm{K}$ intake can increase the risk for hypertension [31]. Previous Se biofortification studies have found decreases or no significant changes in $\mathrm{K}$ content [12, 25, 32, 33]. In our study, cilantro did not exhibit significant changes for K or for any mineral except Se and $\mathrm{Na}$. On the other hand, compared to control, scallions treated with $10.0 \mathrm{mg} \cdot \mathrm{L}^{-1}$ Se increased $\mathrm{K}$ by $91.6 \%$, and basil treated with $5.0 \mathrm{mg} \cdot \mathrm{L}^{-1}$ Se increased $\mathrm{K}$ by $72.2 \%$ (Table 1 ). Previous studies were completed in mature plants instead of microgreens, and the concentration of $\mathrm{K}$ is typically higher in young plant tissues because of the role of $\mathrm{K}$ in photosynthesis, respiration, and water homeostasis [34]. Based on the results, sodium selenate biofortification can enhance K content of both scallions and basil microgreens.

Other major minerals of importance in human health are $\mathrm{P}, \mathrm{Ca}$, and $\mathrm{Mg}$ which are essential components for bone formation, and deficiencies have been related to the risk for osteoporosis [35]. The content of P was significantly increased in scallions by $47.4 \%$ at 10.0 $\mathrm{mg} \cdot \mathrm{L}^{-1}$ Se compared to control and in basil by $42.4 \%$ at $5.0 \mathrm{mg} \cdot \mathrm{L}^{-1}$ Se compared to control (Table 1). However, $\mathrm{P}$ deficiencies are rare due to its ubiquity in foods [36]; whereas, inadequate Ca intake is common among vegans [37]. Further, approximately half of the United States population consumes less than the required amount of $\mathrm{Mg}$ [38]. Even those who strive for better nutrition in whole foods can fall short due to Mg removal during food processing [38]. In our study, $\mathrm{Ca}$ and $\mathrm{Mg}$ content were not affected in basil or cilantro microgreens; however, both minerals increased in scallions at $10.0 \mathrm{mg} \cdot \mathrm{L}^{-1}$ Se by $59.8 \%$. for $\mathrm{Ca}$ and $60.6 \%$ for $\mathrm{Mg}$ (Table 1 ). Wu and Huang [39] also reported increased Ca content in white clover (102.6\%) and tall fescue $(66.7 \%)$ grown in hydroponics at $2.0 \mathrm{mg} \cdot \mathrm{L}^{-1} \mathrm{Se}$ as selenate. Põldma et al. [25] reported an increase of $\mathrm{Mg}$ content in onions grown with a foliar spray of $50 \mathrm{mg} \cdot \mathrm{L}^{-1} \mathrm{Se}$ as selenate. Based on 
the current study on culinary herbs, sodium selenate biofortification has the potential to enhance scallion content of several minerals relevant to bone health, but basil showed an increase in $\mathrm{P}$ content only, while cilantro did not demonstrate alterations in any of these minerals.

Trace elements $\mathrm{Cu}, \mathrm{Fe}, \mathrm{Mn}$, and $\mathrm{Zn}$ also contribute to bone mineralization [35] but are more often studied as co-factors for antioxidant enzymes. Antioxidants have been suggested to have numerous health benefits. In humans, $\mathrm{Cu}, \mathrm{Mn}$, and $\mathrm{Zn}$ are cofactors for superoxide dismutase and Fe a cofactor for catalase [40]. Fe deficiency affects nearly 2 billion people worldwide, with children, women of childbearing age, and pregnant women experiencing a greater incidence [41]. Vegetarians are at risk of consuming inadequate levels of $\mathrm{Zn}$ and may require up to $50 \%$ more $\mathrm{Zn}$ compared to non-vegetarians [42]. Meanwhile, $\mathrm{Cu}$ and $\mathrm{Mn}$ deficiencies are rare [43]. In our study, $\mathrm{Cu}$ demonstrated a significant increase in scallions starting at $5.0 \mathrm{mg} \cdot \mathrm{L}^{-1} \mathrm{Se}$ and continued to increase significantly at $10.0 \mathrm{mg} \cdot \mathrm{L}^{-1} \mathrm{Se}$ (Table 2). The content of $\mathrm{Fe}, \mathrm{Mn}$, and $\mathrm{Zn}$ were all higher $(p<0.05)$ in the $10.0 \mathrm{mg} \cdot \mathrm{L}^{-1} \mathrm{Se}$ group compared to all other Se doses (Table 2). Basil and cilantro did not demonstrate significant changes in $\mathrm{Cu}, \mathrm{Fe}$, Mn, or Zn. (Table 2). Values of these minerals in other Se biofortification studies are highly variable based on plant and Se species, application technique, and dosage $[8,10,33]$. These results show sodium selenate biofortification can increase minerals relevant to antioxidant function in scallion microgreens.

Boron has pleiotropic effects in human nutrition that include antioxidant, antiinflammatory, and bone density [44]. In this study, B content significantly increased in fresh scallions at $10.0 \mathrm{mg} \cdot \mathrm{L}^{-1}$ Se compared to all other treatment groups $(142.2 \%, 100.0 \%$, and $95.0 \%$ increases compared to $0.0,2.5$, and $5.0 \mathrm{mg} \cdot \mathrm{L}^{-1} \mathrm{Se}$, respectively). The content of $\mathrm{B}$ in basil and cilantro was not affected by Se biofortification. In plant nutrition, B is essential for plant growth 
and phenolic metabolism [45]. This is important since plants are a major source of phenolic compounds in the human diet.

\subsubsection{Total Phenolic Content}

A diet rich in plant polyphenols is associated with the prevention of diseases such as: cancer, cardiovascular disease, and diabetes [46]. Accumulation of polyphenols in plants is increased during stressful growing conditions [47]. The presence of excess Se in the soil can contribute to this stress [48]. In the present study, total phenolic content was significantly higher at the highest Se treatment for all herb species (Figure 4). For basil and cilantro, the highest dose of $5.0 \mathrm{mg} \cdot \mathrm{L}^{-1}$ Se treatment achieved the highest phenolic content $(102.6 \%$ and $50.3 \%$ increases for basil and cilantro, respectively); for scallions, the highest dose of $10.0 \mathrm{mg} \cdot \mathrm{L}^{-1} \mathrm{Se}$ treatment achieved the highest total phenols (113.7\% increase) (Figure 4). Increased total phenolic content with increasing Se treatments have also been reported in adult basil, spinach, onion, and lettuce $[9,12,25,49]$. Zheng and Wang [50] reported total phenolic content of $2.23 \mathrm{mg} \mathrm{GAE} \cdot \mathrm{g}^{-1} \mathrm{FW}$ for basil, and Zhan et al. [51] reported $0.20 \mathrm{mg} \mathrm{GAE} \cdot \mathrm{g}^{-1} \mathrm{FW}$ for scallions, values comparable to the control groups in our study (1.91 and $0.29 \mathrm{mg} \mathrm{GAE} \cdot \mathrm{g}^{-1} \mathrm{FW}$ for control basil and scallions, respectively).

However, total phenolic content can vary widely for the same plant species. Henning et al. [52] demonstrated total phenol content of adult basil and cilantro at 8.70 and $6.10 \mathrm{mg} \mathrm{GAE} \cdot \mathrm{g}^{-1}$ FW, respectively. In our study, control basil and cilantro accumulated less phenols at 1.91 and $1.49 \mathrm{mg} \mathrm{GAE} \cdot \mathrm{g}^{-1} \mathrm{FW}$, respectively. These lower values may be due to the difference in stages of harvest. McCance et al. [53] reported a decrease in total phenolic content in three cultivars of purple basil with earlier stages of harvest. Total phenolic content may also vary depending on other factors such as growing conditions and differences in extraction techniques. 
Overall, results showed sodium selenate biofortification enhanced phenolic content of microgreen herbs along with Se content. This adds to the nutritional benefits of biofortification with $5.0 \mathrm{mg} \cdot \mathrm{L}^{-1} \mathrm{Se}$ in basil and cilantro and $10.0 \mathrm{mg} \cdot \mathrm{L}^{-1} \mathrm{Se}$ in scallions. Further, Xiao et al. [54] reported that phenolic content in microgreens was positively correlated with consumer perception of overall eating quality and acceptability of flavor $(r=0.66$ and $r=0.58$, respectively). This suggests that biofortified culinary herb microgreens offer the benefits of enhanced dietary intake of Se and antioxidant phenolic compounds while improving consumer acceptability.

\subsubsection{Total Antioxidant Capacity}

Measuring total antioxidant capacity in terms of biologically relevant free radicals can assess multiple antioxidant compounds and their complex interactions to elucidate potential in humans [55]. ORAC is commonly used to assess antioxidant capacity of foods and provides a unique in vitro assessment considering the most common free radicals in lipid oxidation in vivo [56]. Hydrophilic and lipophilic ORAC values are important to consider when analyzing food, as both hydrophilic (ascorbic acid, flavonoids, polyphenols) and lipophilic (carotenoids and tocopherols) antioxidants can be beneficial to human health [57]. For all herb species, the hydrophilic, lipophilic, and total ORAC values were significantly $(p<0.05)$ higher at the highest Se treatment compared to control groups (Figure 5A-C). Similarly, Guardado-Felix et al. [58] demonstrated an increase in ORAC for chickpea sprouts treated with increasing levels of Se.

In the current study, scallions at the highest dose of $10.0 \mathrm{mg} \cdot \mathrm{L}^{-1} \mathrm{Se}$ and basil and cilantro at the highest dose of $5.0 \mathrm{mg} \cdot \mathrm{L}^{-1}$ Se resulted in microgreen herbs with the highest total antioxidant capacity as measured by ORAC $(152.2 \%, 68.6 \%$, and $66.0 \%$ increases in scallions, basil, and cilantro, respectively) (Figure 5C). However, plant yield was decreased in scallions 
and basil at these treatments. Rios et al. [59] reported increases in antioxidant enzymes such as glutathione peroxidase and superoxide dismutase with a concomitant decrease in lettuce shoot biomass at the highest concentration of Se treatment $\left(9.5 \mathrm{mg} \cdot \mathrm{L}^{-1}\right)$ as selenate. At high treatment doses, Se can act as a pro-oxidant in plants and causes oxidative stress which contributes to Se toxicity [59]. To counteract oxidative stress, plants increase their antioxidant defenses [4]. However, toxicity symptoms, such as decreased plant growth, can result if reactive oxygen species (ROS) overwhelm the plant's antioxidant defenses. This may explain the increases in total ORAC occurring alongside decreases in yield for basil and scallions observed in our study. Interestingly, scallions at $5.0 \mathrm{mg} \cdot \mathrm{L}^{-1} \mathrm{Se}$ did not demonstrate significant increases in ORAC, indicating biofortification was able to enhance antioxidant capacity in basil and cilantro at lower concentrations. However, cilantro demonstrated increases in ORAC without a decreased plant yield, suggesting cilantro's antioxidant defenses were adequate to quench ROS induced by Se uptake.

\subsection{Conclusions}

Sodium selenate biofortification affected Se as well as the content of other dietary minerals, total phenolics, and total antioxidant capacity in all culinary herb microgreens studied. Se content, total phenolic content, and total antioxidant capacity increased at the highest Se dose for all herb species. Se biofortification induced increases in total phenolics and antioxidant capacity at lower doses for basil and cilantro compared to scallions. However, scallions at 10.0 $\mathrm{mg} \cdot \mathrm{L}^{-1}$ Se accumulated the most total Se, suggesting scallions have the greatest potential as a functional food despite having a decrease in crop yield at this dose. These results suggest a tradeoff between supplying supra-adequate levels of Se to the diet and causing detrimental effects on plant growth. Navarro-Alarcon and Cabrera-Vique [1] note that plants serve as an effective 
buffer to Se toxicity in humans because of decreased plant yield with excessively high levels. In the United States, mean Se intake from food is $115 \mu \mathrm{g}$ per day, while the toxicity threshold is $400 \mu \mathrm{g}$ per day [60-61]. This suggests that scallions at the $10.0 \mathrm{mg} \cdot \mathrm{L}^{-1} \mathrm{Se}$ treatment, which accumulated $324.2 \mu \mathrm{g} \cdot \mathrm{g}^{-1} \mathrm{FW}$ could result in toxicity symptoms when supplemented to the average American diet. However, it is also relevant to consider a practical amount to be consumed. One gram of scallions at $10.0 \mathrm{mg} \cdot \mathrm{L}^{-1}$ Se would approximate 100 individual scallion microgreens, a value unlikely to be consumed in one day. A realistic serving size of 10 fresh scallion microgreens would supplement about $32 \mu \mathrm{g}$ of Se. While scallions at $10.0 \mathrm{mg} \cdot \mathrm{L}^{-1} \mathrm{Se}$ may be unfavorable from a grower's perspective due to decreases in yield, these scallions offer a dietary supplement of Se with the added benefit of increased total phenolics, antioxidant capacity, and content of other minerals important to human health including $\mathrm{S}, \mathrm{Na}, \mathrm{K}, \mathrm{P}, \mathrm{Ca}, \mathrm{Mg}$, $\mathrm{Cu}, \mathrm{Fe}, \mathrm{Mn}, \mathrm{Zn}$, and B. Scallions at $5.0 \mathrm{mg} \cdot \mathrm{L}^{-1} \mathrm{Se}$ may be favorable to growers since yield was not affected with the large increase of Se content; however, effects on other minerals and antioxidants were insignificant. Basil and cilantro at $5.0 \mathrm{mg} \cdot \mathrm{L}^{-1} \mathrm{Se}$ offer a lesser amount of Se, but with increases in antioxidants. A serving size of 10 fresh microgreens of basil or cilantro at $5.0 \mathrm{mg} \cdot \mathrm{L}^{-1}$ Se would approximate 19 and $15 \mu \mathrm{g}$ of Se, respectively. While biofortified basil offers the additional human nutrition benefit of elevated contents of S, K, P, cilantro's absence of decreased yield can make cilantro preferable to growers. Overall, the study results confirm the hypothesis that sodium selenate biofortification of culinary herb microgreens in hydroponic conditions can produce functional foods to improve human health by increasing Se content with the added benefits of enhancing several dietary minerals as well as antioxidant content. 


\subsection{References}

1. Navarro-Alarcon M, Cabrera-Vique C (2008) Selenium in food and the human body: A review. Sci Total Environ. 400(1-3):115-141.

2. Combs GF (2001) Selenium in global food systems. Br J Nutr. 85(5):517-547.

3. Rayman MP (2008) Food-chain selenium and human health: emphasis on intake. Br J Nutr. 100(2):254-268.

4. Gupta M, Gupta S (2017) An overview of selenium uptake, metabolism, and toxicity in plants. Front Plant Sci. 7:2074

5. Saha U, Fayiga A, Sonon L (2017) Selenium in the soil-plant environment: A review. Int J Appl Agric Sci. 3(1):1-18.

6. Terry N, Zayed AM, de Souza MP, Tarun AS (2000) Selenium in higher plants. Annu Rev Plant Physiol Plant Mol Biol. 51(1):401-432.

7. Puccinelli M, Malorgio F, Pezzarossa B (2017) Selenium enrichment of horticultural crops. Molecules. 22(6):933.

8. Boldrin PF, Faquin V, Ramos SJ, Boldrin KVF, Ávila FW, Guilherme LRG (2013) Soil and foliar application of selenium in rice biofortification. J Food Compos Anal. 31(2):238-244.

9. Hawrylak-Nowak B (2008) Enhanced selenium content in sweet basil (Ocimum basilicum) by foliar fertilization. Veg Crop Res Bul. 69:63-72.

10. He PP, Lv XZ, Wang GY (2004) Effects of Se and Zn supplementation on the antagonism against $\mathrm{Pb}$ and $\mathrm{Cd}$ in vegetables. Environ Int. 30(2):167-172.

11. Malagoli M, Schiavon M, dall'Acqua S, Pilon-Smits EAH (2015) Effects of selenium biofortification on crop nutritional quality. Front Plant Sci. 6:280. 
12. Saffaryazdi A, Lahouti M, Ganjeali A, Bayat H (2012) Impact of selenium supplementation on growth and selenium accumulation on spinach (Spinacia oleracea L.) plants. Not Sci Biol. 4(4):95-100.

13. Manero J, Phillips C, Ellison B, Lee S, Nickols-Richarson SM, Chapman-Novakofski KM (2017) Influence of seasoning on vegetable selection, liking and intent to purchase. Appetite. 116:239-245.

14. Peters JC, Polsky S, Stark R, Zhaoxing P, Hill JO (2014) The influence of herbs and spices on overall liking of reduced fat food. Appetite. 79:183-188.

15. Savage JS, Peterson J, Marini M, Bordi PL, Birch LL (2013) The addition of a plain or herbflavored reduced-fat dip is associated with improved preschoolers' intake of vegetables. J Acad Nutr Diet. 113(8):1090-1095.

16. Choe U, Yu LL, Wang TTY (2018) The science behind microgreens as an exciting new food for the $21^{\text {st }}$ century. J Agric Food Chem. 66(44):11519-11530.

17. Dumont E, Vanhaecke F, Cornelis R (2006) Selenium speciation from food source to metabolites: A critical review. Anal Bioanal Chem 385(7):1304-1323.

18. Barickman TC, Kopsell DA, Sams CE (2012) Selenium influences glucosinolate and isothiocyanates and increases sulfur uptake in Arabidopsis thaliana and rapid-cycling Brassica oleracea. J Agric Food Chem. 61(1):202-209.

19. U.S. Environmental Protection Agency (1996). Method 3052: Microwave assisted acid digestion of siliceous and organically based matrices. U.S. EPA, Washington, DC.

20. Nicolle C, Carnat A, Fraisse D, et al (2004) Characterisation and variation of antioxidant micronutrients in lettuce (Lactuca sativa folium). J Sci Food Agric. 84(15):2061-2069. 
21. Waterland NL, Moon Y, Tou JC, Kopsell DA, Kim MJ, Park S (2019) Differences in leaf color and stage of development at harvest influenced phytochemical content in three cultivars of kale (Brassica oleracea L. and B. napus). J Agric Sci. 11(3):14-21.

22. Ou B, Chang T, Huag D, Prior RL (2013) Determination of total antioxidant capacity by oxygen radical absorbance capacity (ORAC) using fluorescein as the fluorescence probe: First action 2012.23. J AOAC Int. 96(6):1372-1376.

23. Kopsell DA, Sams CE, Barickman TC, Deyton DE (2009) Selenization of basil and cilantro through foliar applications of selenate-selenium and selenite-selenium. HortSci. 44(2):438442.

24. Puccinelli M, Malorgio F, Rosellini I, Pezzarossa B (2017) Uptake and partitioning of selenium in basil (Ocimum basilicum L.) plants grown in hydroponics. Sci Hortic. 225:271276.

25. Põldma P, Moor U, Tõnutare T, Herodes K, Rebane R (2013) Selenium treatment under field conditions affects mineral nutrition, yield, and antioxidant properties of bulb onion (Allium cepa L.). Acta Sci Pol. Hortorum Cultus. 12(6):167-181.

26. Smoleń S, Skoczylas L, Ledwożyw-Smoleń S, et al (2016) Biofortification of carrot (Daucaus carota L.) with iodine and selenium in a field experiment. Front Plant Sci. 7:730.

27. Rios JJ, Blasco B, Cervilla LM, Rubio-Wilhelmi MM, Ruiz JM, Romero L (2008) Regulation of sulphur assimilation in lettuce plants in the presence of selenium. Plant Growth Regul. 56(1):43-51.

28. Hawrylak-Nowak B (2013) Comparative effects of selenite and selenate on growth and selenium accumulation in lettuce plants under hydroponic conditions. Plant Growth Regul. 70(2):149-157. 
29. Parcell SW (2002) Sulfur in human nutrition and applications in medicine. Altern Med Rev $7(1): 22-44$.

30. U.S. Department of Health and Human Services and U.S. Department of Agriculture. (2015) 2015 - 2020 Dietary Guidelines for Americans. Health.gov. https://health.gov/dietaryguidelines/2015/resources/2015-2020_Dietary_Guidelines.pdf. Accessed on February 10, 2019.

31. Adrogué HJ, Madias NE (2014) The impact of sodium and potassium on hypertension risk. Semin Nephrol. 34(3):257-272.

32. Põldma P, Tõnutare T, Viitak A, Luik A, Moor U (2011) Effect of selenium treatment on mineral nutrition, bulb size, and antioxidant properties of garlic (Allium sativum L.). J Agric Food Chem. 59(10):5498-5503.

33. Rios JJ, Blasco B, Leyva R, et al (2013) Nutritional balance changes in lettuce plant grown under different doses and forms of selenium. J Plant Nutr. 36(9):1344-1354.

34. Waterland NL, Moon Y, Tou JC, Kim MJ, Pena-Yewtukhiw EM, Park S (2017) Mineral content differs among microgreen, baby leaf, and adult stages in three cultivars of kale 52(4):566-571.

35. Palacios C (2006) The role of nutrients in bone health, from A to Z. Crit Rev Food Sci Nutr. 46(8):621-628.

36. Bonjour JP, Gueguen L, Palacios C, Shearer MJ, Weaver CM (2009) Minerals and vitamins in bone health: The potential value of dietary enhancement. Br J Nutr. 101(11):1581-1596.

37. Clarys P, Deliens T, Huybrechts I, et al (2014) Comparison of nutritional quality of the vegan, vegetarian, semi-vegetarian, pesco-vegetarian and omnivorous diet. Nutrients. 6(3):1318-1332. 
38. Razzaque MS (2018) Magnesium: Are we consuming enough? Nutrients. 10(12):1863.

39. Wu L and Huang ZZ (1992) Selenium assimilation and nutrient element uptake in white clover and tall fescue under the influence of sulphate concentration and selenium tolerance of the plants. J Exp Bot. 43(4):549-555.

40. Soetan KO, Olaiya CO, Oyewole OE (2010) The importance of mineral elements for humans and domestic animals and plants: A review. Afr J Food Sci. 4(5):200-222.

41. Zimmermann MB, Hurrell RF (2007) Nutritional iron deficiency. Lancet. 370(9586):511520.

42. Hunt JR (2003) Bioavailability of iron, zinc, and other trace minerals from vegetarian diets. J Am J Clin Nutr. 78(3):633S-639S.

43. Zheng Y, Li XK, Wang Y, Cai L (2008) The role of zinc, copper, and iron in the pathogenesis of diabetes and diabetic complications: therapeutic effects by chelators. Hemoglobin. 32(1-2):135-145.

44. Khaliq H, Juming Z, Ke-Mei P. (2018) The physiological role of boron on health. Biol Trace Elem Res. 186(1):31-51.

45. Shireen F, Nawaz MA, Chen C, et al (2018) Boron: Functions and approaches to enhance its availability in plants for sustainable agriculture. Int J Mol Sci. 19(7):1856.

46. Pandey KB, Rizvi SI (2009) Plant polyphenols as dietary antioxidants in human health and disease. Oxid Med Cell Longev. 2(5):270-278.

47. Kulbat K. (2016) The role of phenolic compounds in plant resistance. Biotech Food Sci. 80(2): 97-108.

48. Feng R, Wei C, Tu S (2013). The roles of selenium in protecting plants against abiotic stresses. Environ Exper Bot. 87:58-68. 
49. Ríos JJ, Rosales MA, Blasco B, Cervilla LM, Romero L, Ruiz JM (2008) Biofortification of Se and induction of the antioxidant capacity in lettuce plants. Sci Hortic. 116(3):248-255.

50. Zheng W, Wang SY (2001) Antioxidant activity and phenolic compounds in selected herbs. J Agric Food Chem. 49(11):5165-5170.

51. Zhan L, Ma Y, Zhang C, Li L, Pang L, Huang X (2018) Antioxidants and antioxidant capacity in leafy, stem, and fruit vegetables including 50 species. J Food Eng Technol. $7(1): 8-15$.

52. Henning SM, Zhang, Y, Seeram NP, et al (2011) Antioxidant capacity and phytochemical content of herbs and spices in dry, fresh, and blended herb paste form. Int J Food Sci Nutr. 62(3):219-225.

53. McCance KR, Flanigan PM, Quick MM, Niemeyer ED (2016) Influence of plant maturity on anthocyanin concentrations, phenolic composition, and antioxidant properties of 3 purple basil (Ocimum basilicum L.) cultivars. J Food Compost Anal 53:30-39.

54. Xiao Z, Lester GE, Park E, Saftner RA, Luo Y, Wang Q (2015) Evaluation and correlation of sensory attributes and chemical compositions of emerging fresh produce: Microgreens. Postharvest Biol Technol 110:140-148.

55. Blasa M, Gennari L, Angelino D, Ninfali P (2009) Fruit and vegetable antioxidants in health. In: RR Watson \& VR Preedy (Eds.), Bioactive foods in promoting health: fruits and vegetables, $1^{\text {st }}$ edn. Elsevier Inc., London pp. 37-58

56. Shahidi F, Zhong Y (2015) Measurement of antioxidant activity. J Funct Foods. 18:757-781.

57. Cho Y, Yeum K, Chen C, et al (2007) Phytonutrients affecting hydrophilic and lipophilic antioxidant activities in fruits, vegetables, and legumes. J Sci Food Agric. 87(6):1096-1107. 
58. Guardado-Felix D, Serna-Saldivar SO, Cuevas-Rodriguez EO, Jacobo-Velazquez DA, Gutierrez-Uribe (2017) Effect of sodium selenite on isoflavonoid contents and antioxidant capacity of chickpea (Cicer arietinum L.) sprouts. Food Chem. 226:69-74.

59. Rios JJ, Blasco B, Cervilla LM, et al (2009) Production and detoxification of $\mathrm{H}_{2} \mathrm{O}_{2}$ in lettuce plants exposed to selenium. Ann Appl Biol. 154:107-116.

60. U.S. Department of Agriculture, Agricultural Research Service. (2018) Nutrient Intakes from Food and Beverages: Mean Amounts Consumed per Individual, by Gender and Age, What We Eat in America, NHANES 2015-2016. https://www.ars.usda.gov/ARSUserFiles/80400530/pdf/1516/Table_1_NIN_GEN_15.pdf Accessed on February 28, 2019.

61. Food and Nutrition Board \& Institute of Medicine (2000) Dietary Reference Intakes: Vitamin C, Vitamin E, Selenium, and Carotenoids. Washington, DC: National Academy Press. 
Table 1. Major mineral content of scallion, basil, and cilantro microgreens treated with different concentrations of Se as sodium selenate, on a fresh weight basis. ${ }^{2}$

\begin{tabular}{|c|c|c|c|c|c|c|c|c|c|c|c|c|c|c|c|}
\hline \multirow{4}{*}{$\begin{array}{l}\text { Treatment } \\
\left(\mathbf{m g} \cdot \mathbf{L}^{-1} \mathrm{Se}\right)\end{array}$} & \multicolumn{3}{|c|}{$\mathrm{Na}$} & \multicolumn{3}{|c|}{$\mathbf{K}$} & \multicolumn{3}{|c|}{$\mathbf{P}$} & \multicolumn{3}{|c|}{ Ca } & \multicolumn{3}{|c|}{$\mathrm{Mg}$} \\
\hline & & & & & & & \multicolumn{3}{|c|}{ Species } & \multirow{3}{*}{ Scallion } & \multirow[b]{2}{*}{ Basil } & \multirow{3}{*}{ Cilantro } & \multirow{3}{*}{ Scallion } & \multirow{3}{*}{ Basil } & \multirow{3}{*}{ Cilantro } \\
\hline & Scallion & Basil & Cilantro & Scallion & Basil & Cilantro & Scallion & Basil & Cilantro & & & & & & \\
\hline & & & & & & & ----------- & $\mathrm{mg} \cdot \mathrm{g}^{-1} \mathrm{FV}$ & & & & & & & \\
\hline 0.0 & $0.003 \mathrm{~b}$ & $0.005 \mathrm{a}$ & $0.009 \mathrm{c}$ & $2.25 \mathrm{~b}$ & $1.62 \mathrm{~b}$ & $4.71 \mathrm{a}$ & $0.38 \mathrm{~b}$ & $0.33 \mathrm{~b}$ & $0.61 \mathrm{a}$ & $0.97 \mathrm{~b}$ & $1.03 \mathrm{a}$ & $0.90 \mathrm{a}$ & $0.33 \mathrm{~b}$ & $0.30 \mathrm{a}$ & $0.49 \mathrm{a}$ \\
\hline 2.5 & $0.007 \mathrm{~b}$ & $0.010 \mathrm{a}$ & $0.021 \mathrm{~b}$ & $2.66 \mathrm{~b}$ & $2.26 \mathrm{ab}$ & $4.30 \mathrm{a}$ & $0.38 \mathrm{~b}$ & $0.43 \mathrm{ab}$ & $0.59 \mathrm{a}$ & $1.13 \mathrm{~b}$ & $1.24 \mathrm{a}$ & $0.79 \mathrm{a}$ & $0.39 \mathrm{~b}$ & $0.38 \mathrm{a}$ & $0.44 \mathrm{a}$ \\
\hline 5.0 & $0.013 \mathrm{~b}$ & $0.022 \mathrm{a}$ & $0.040 \mathrm{a}$ & $2.94 \mathrm{ab}$ & $2.79 \mathrm{a}$ & $4.88 \mathrm{a}$ & $0.38 \mathrm{~b}$ & $0.47 \mathrm{a}$ & $0.66 \mathrm{a}$ & $1.12 \mathrm{~b}$ & $1.32 \mathrm{a}$ & $0.76 \mathrm{a}$ & $0.39 \mathrm{~b}$ & $0.39 \mathrm{a}$ & $0.46 \mathrm{a}$ \\
\hline 10.0 & $0.053 \mathrm{a}$ & - & - & $4.31 \mathrm{a}$ & - & - & $0.56 \mathrm{a}$ & - & - & $1.55 \mathrm{a}$ & - & - & $0.53 \mathrm{a}$ & - & - \\
\hline
\end{tabular}

${ }^{2}$ Values expressed as mean for 3 replications of each herb species.

For each given nutrient within species, mean values connected by the same letter are not significantly different with Tukey's significance test at $p<0.05$. Abbreviations and symbols: Na, sodium; K, potassium; P, phosphorus; Ca, calcium; Mg, magnesium; Se, selenium; FW, fresh weight. 
Table 2. Trace mineral content of scallion, basil, and cilantro microgreens treated with different concentrations of Se as sodium selenate, on a fresh weight basis. ${ }^{\mathrm{z}}$

\begin{tabular}{|c|c|c|c|c|c|c|c|c|c|c|c|c|}
\hline \multirow{4}{*}{$\begin{array}{l}\text { Treatment } \\
\left(\mathrm{mg} \cdot \mathbf{L}^{-1} \mathrm{Se}\right)\end{array}$} & \multicolumn{3}{|c|}{$\mathbf{C u}$} & \multicolumn{3}{|c|}{$\mathrm{Fe}$} & \multicolumn{3}{|c|}{ Mn } & \multicolumn{3}{|c|}{$\mathbf{Z n}$} \\
\hline & \multicolumn{12}{|c|}{$\overline{\text { Species }}$} \\
\hline & Scallion & Basil & Cilantro & Scallion & Basil & Cilantro & Scallion & Basil & Cilantro & Scallion & Basil & Cilantro \\
\hline & \multicolumn{12}{|c|}{ } \\
\hline 0.0 & $0.25 \mathrm{c}$ & $0.34 \mathrm{a}$ & $0.48 \mathrm{a}$ & $6.71 \mathrm{~b}$ & $8.90 \mathrm{a}$ & $6.73 \mathrm{a}$ & $2.78 \mathrm{~b}$ & $3.71 \mathrm{a}$ & $4.40 \mathrm{a}$ & $1.57 \mathrm{~b}$ & $1.49 \mathrm{a}$ & $3.52 \mathrm{a}$ \\
\hline 2.5 & $0.28 \mathrm{c}$ & $0.39 \mathrm{a}$ & $0.46 \mathrm{a}$ & $5.64 \mathrm{~b}$ & $7.29 \mathrm{a}$ & $11.44 \mathrm{a}$ & $3.26 \mathrm{~b}$ & $4.43 \mathrm{a}$ & $3.46 \mathrm{a}$ & $1.69 \mathrm{~b}$ & $1.68 \mathrm{a}$ & $3.39 \mathrm{a}$ \\
\hline 5.0 & $0.35 \mathrm{~b}$ & $0.41 \mathrm{a}$ & $0.62 \mathrm{a}$ & $8.00 \mathrm{~b}$ & $7.30 \mathrm{a}$ & $10.44 \mathrm{a}$ & $3.30 \mathrm{~b}$ & $5.00 \mathrm{a}$ & $4.10 \mathrm{a}$ & $1.88 \mathrm{~b}$ & $1.94 \mathrm{a}$ & $4.20 \mathrm{a}$ \\
\hline 10.0 & $0.48 \mathrm{a}$ & - & - & $14.62 \mathrm{a}$ & - & - & $5.65 \mathrm{a}$ & - & - & $3.10 \mathrm{a}$ & - & - \\
\hline
\end{tabular}

${ }^{\mathrm{z}}$ Values expressed as mean for 3 replications of each herb species.

For each given nutrient within species, mean values connected by the same letter are not significantly different with Tukey's significance test at $p<0.05$.

Abbreviations and symbols: $\mathrm{Cu}$, copper; Fe, iron; Mn, manganese, Zn, zinc; Se, selenium; FW, fresh weight. 
A.

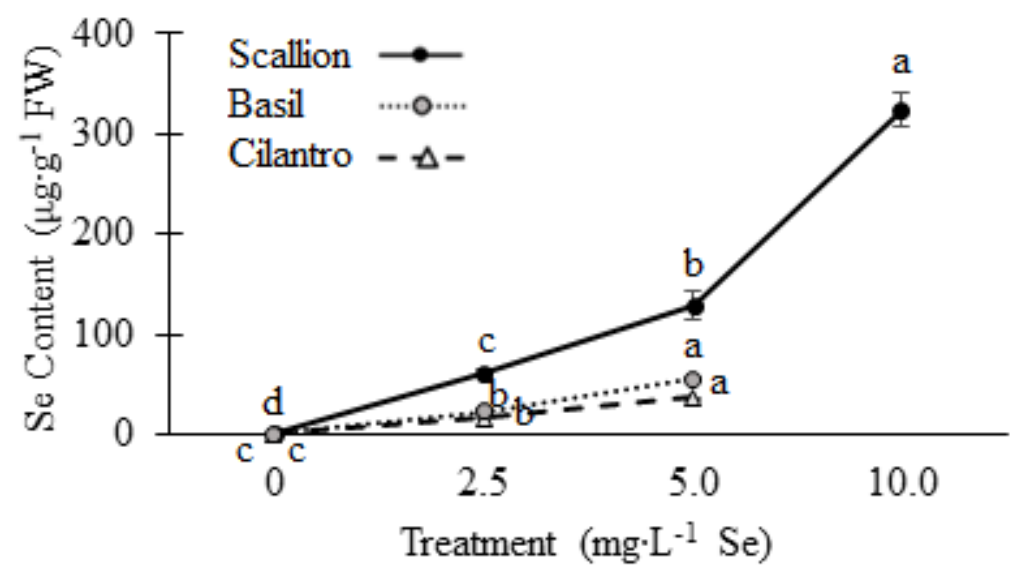

B.

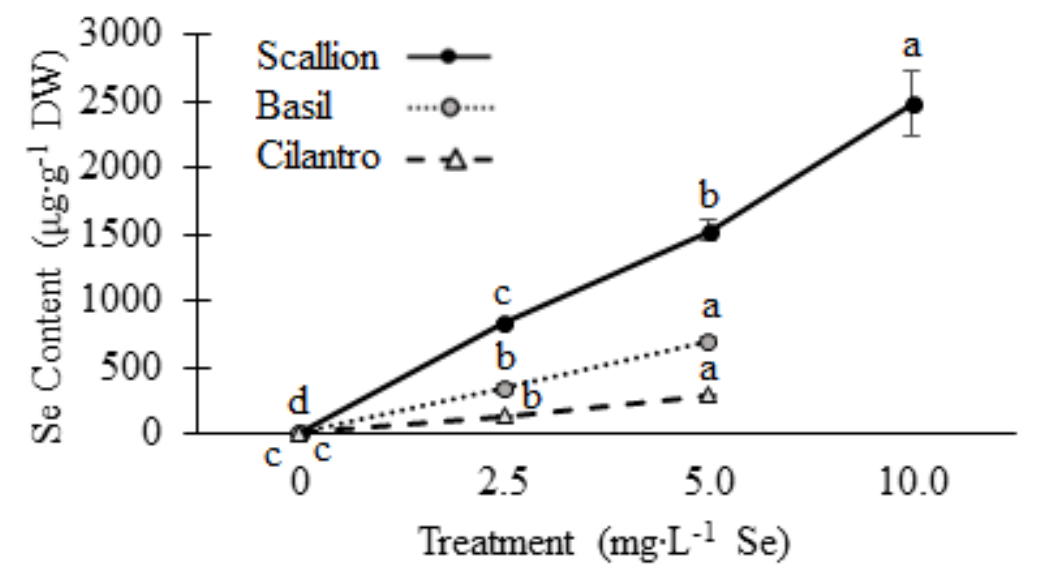

Figure 1. Se content of scallion, basil, and cilantro microgreens treated with different concentrations of Se as sodium selenate, on a fresh weight (A.) and dry weight (B.) basis. Points represent mean and error bars indicate standard error of the mean for 3 replications of each herb species. Mean separation within species not among species. Means connected with the same letter are not significantly different with Tukey's significance test at $p<0.05$. Abbreviations and symbols: Se, selenium; FW, fresh weight; DW, dry weight. 
A.

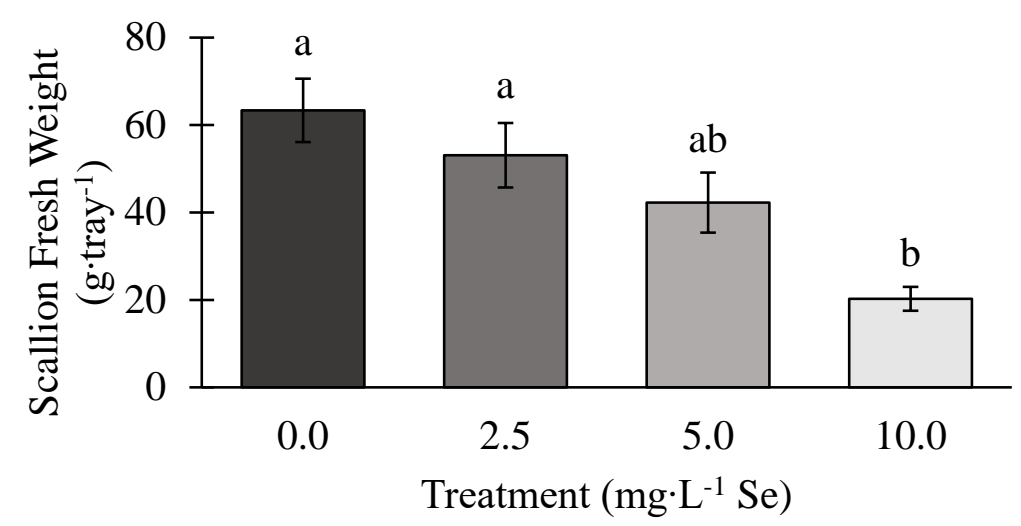

C.

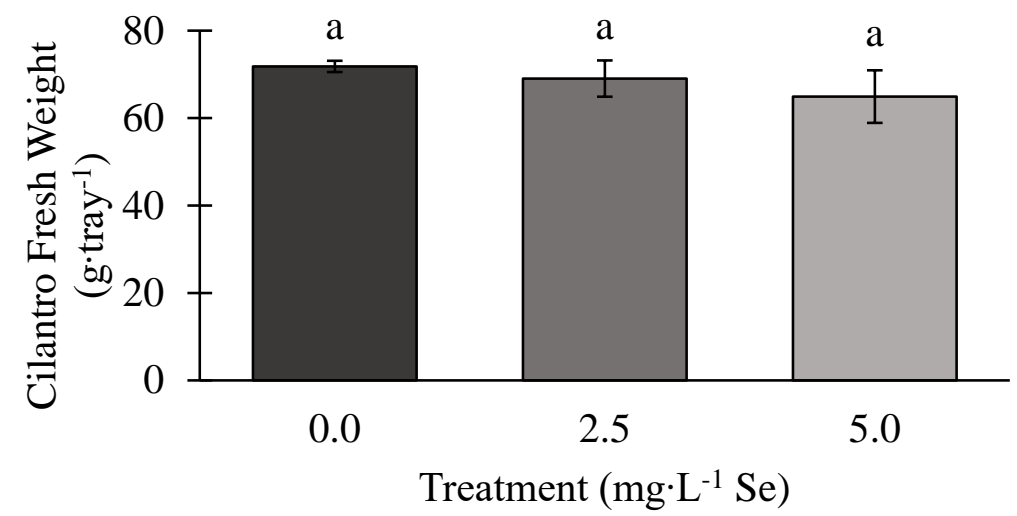

B.

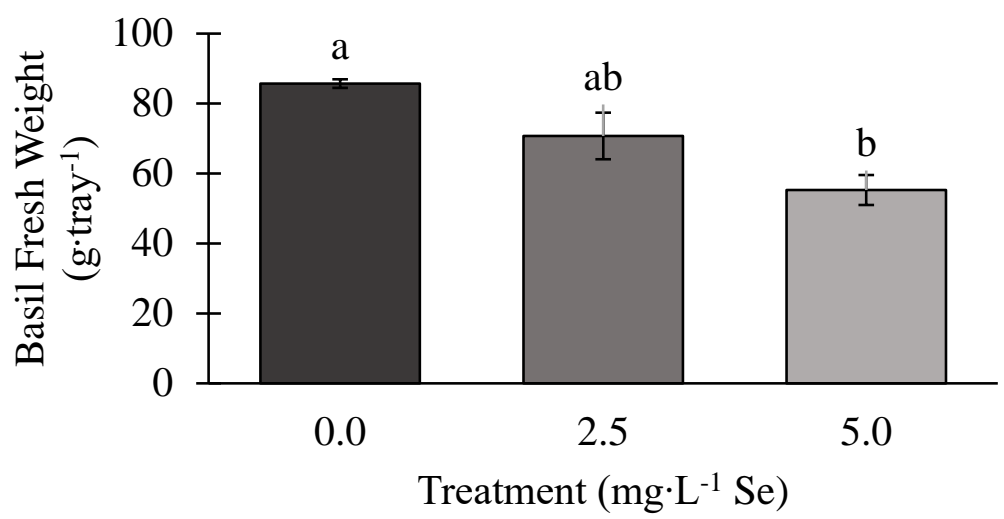

Figure 2. Fresh weight yield of scallion (A.), basil (B.), and cilantro (C.) microgreens treated with different concentrations of Se as sodium selenate. Bars represent mean and error bars indicate standard error of the mean for 3 replications of basil and cilantro, 6 replications for scallions. Means connected with the same letter are not significantly different with Tukey's significance test at $p<$ 0.05. Abbreviations and symbols: Se, selenium. 


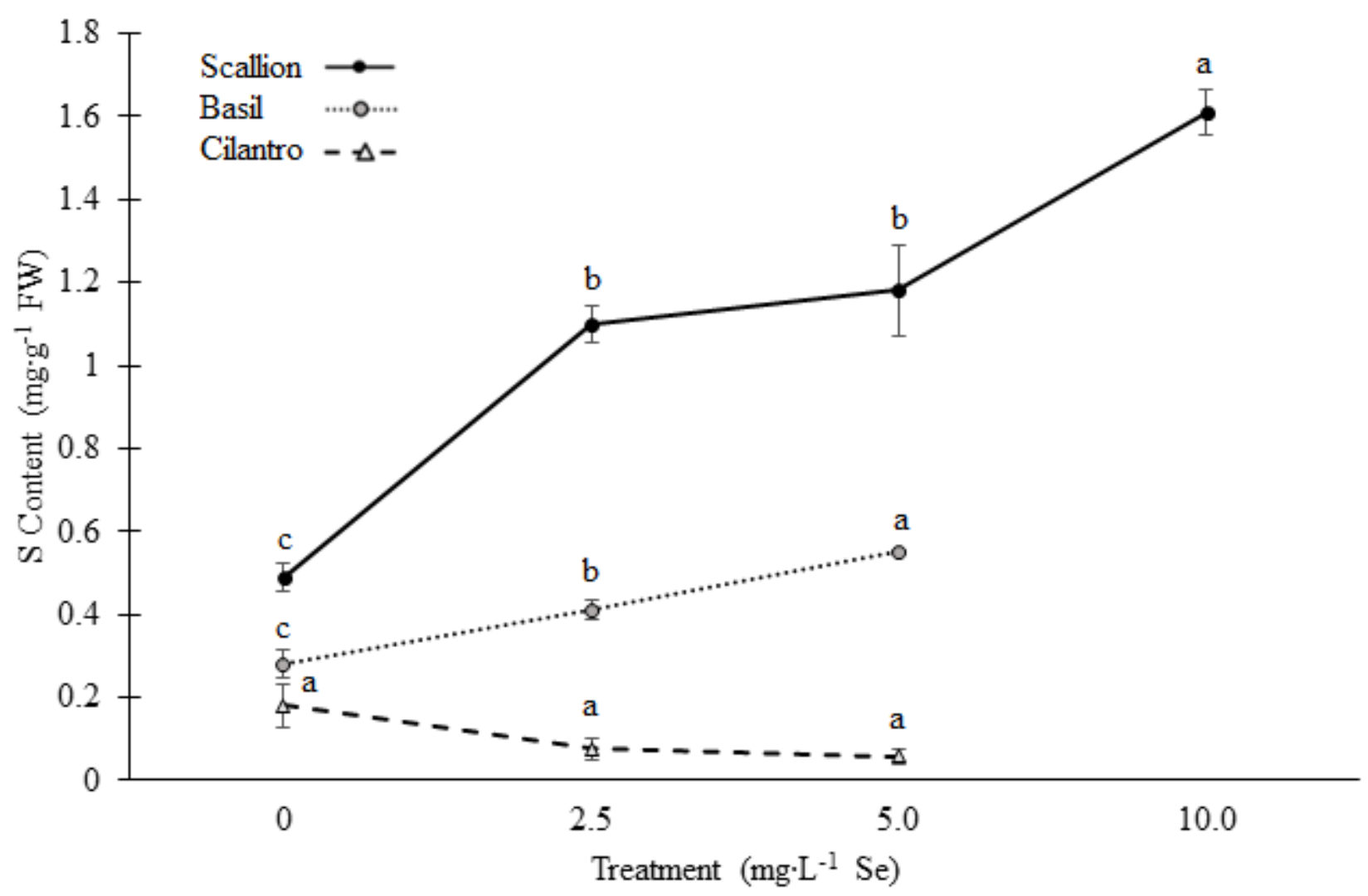

Figure 3. S content of scallion, basil, and cilantro microgreens treated with different concentrations of Se as sodium selenate, on a fresh weight basis. Points represent mean and error bars indicate standard error of the mean for 3 replications of each herb species. Mean separation within species not among species. Means connected with the same letter are not significantly different with Tukey's significance test at $p<0.05$. Abbreviations and symbols: $\mathrm{S}$, sulfur; Se, selenium; FW, fresh weight. 


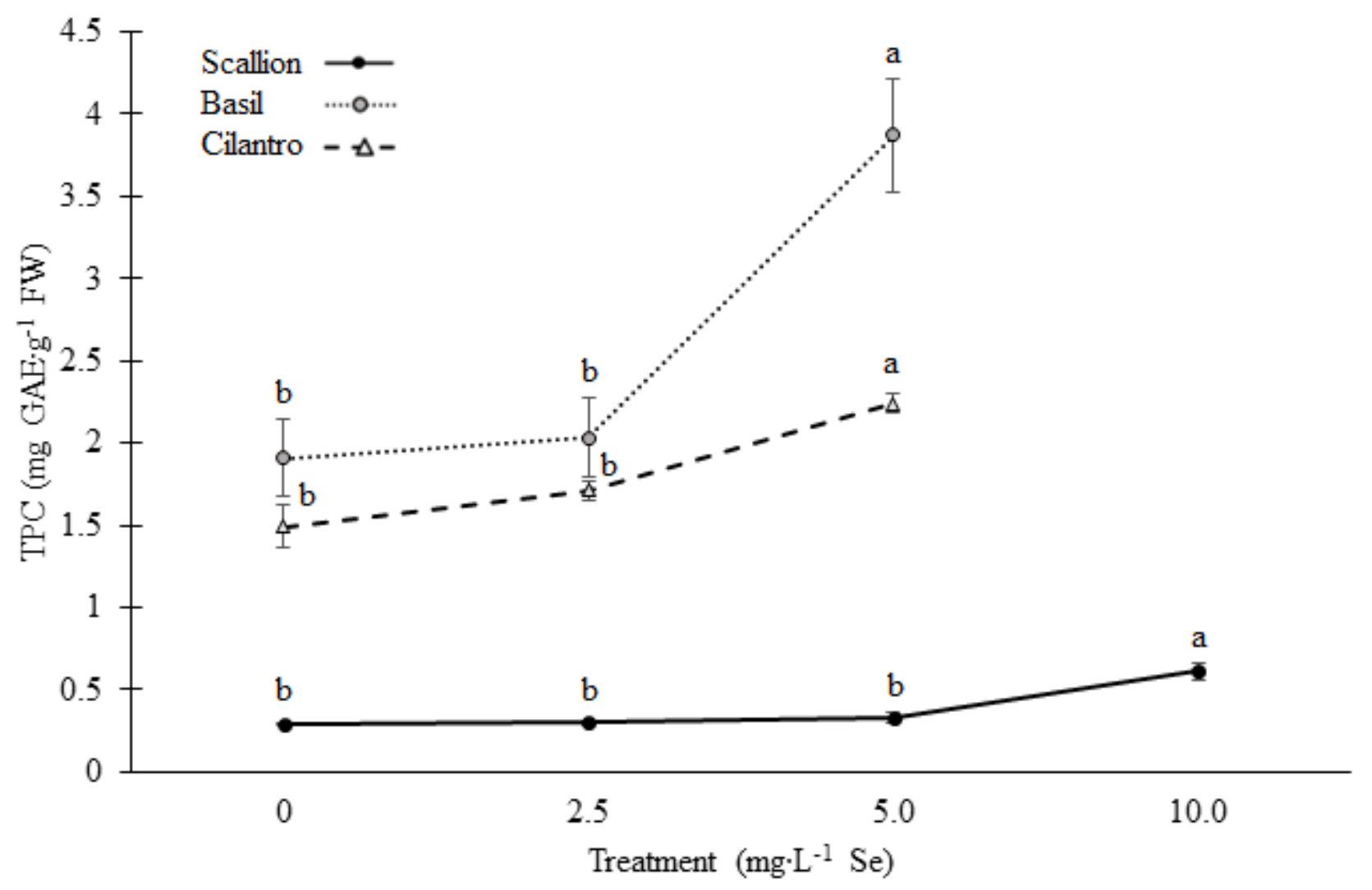

Figure 4. Total phenolic content of scallion, basil, and cilantro microgreens treated with different concentrations of Se as sodium selenate, on a fresh weight basis. Points represent mean and error bars indicate standard error of the mean for 3 replications of each herb species. Mean separation within species not among species. Means connected with the same letter are not significantly different with Tukey's significance test at $p<0.05$. Abbreviations and symbols: TPC, total phenolic content; GAE, gallic acid equivalents; FW, fresh weight; Se, selenium. 
A.

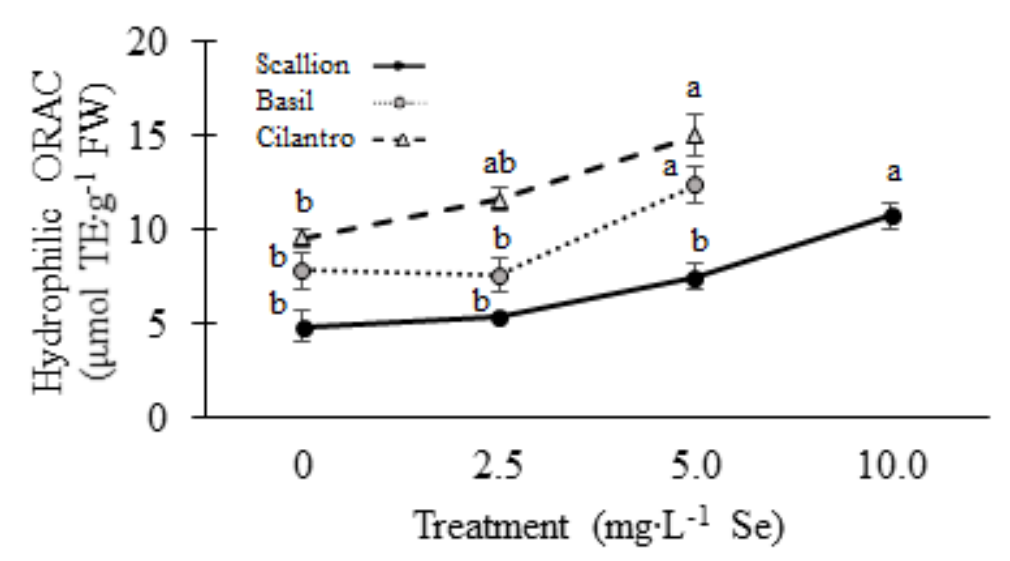

c.

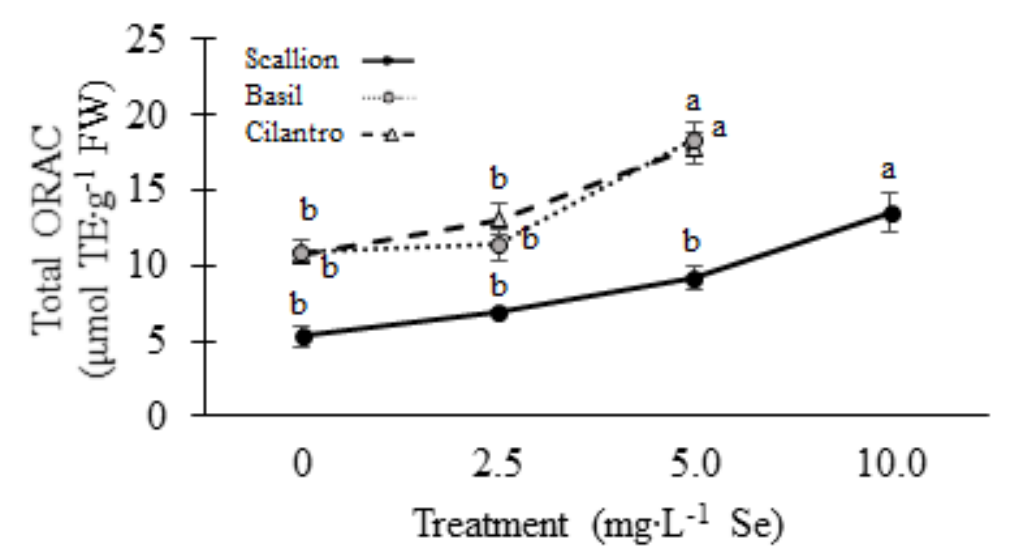

B.

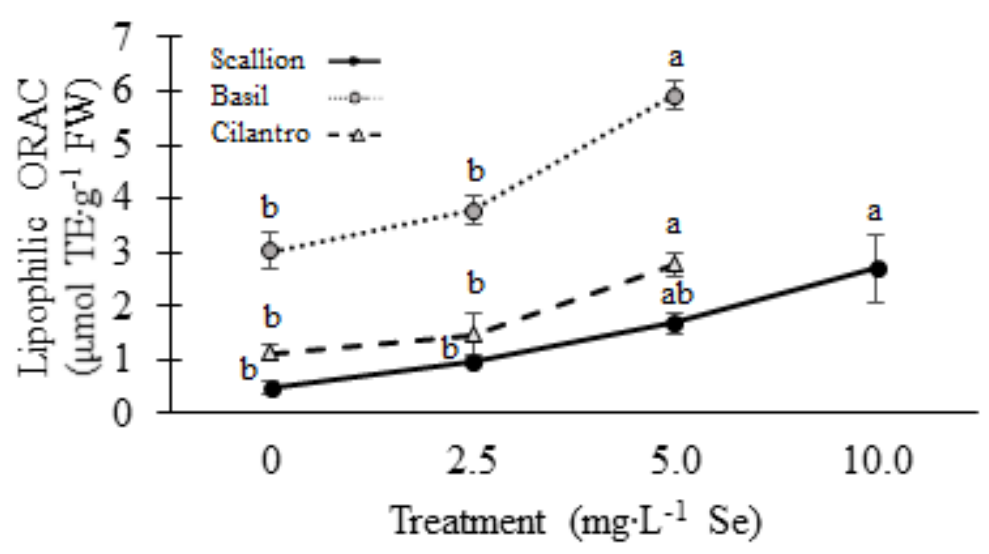

Figure 5. Hydrophilic (A.), lipophilic (B.), and total (C.) ORAC values for scallion, basil, and cilantro microgreens treated with different concentrations of Se as sodium selenate, on a fresh weight basis. Points represent mean and error bars indicate standard error of the mean for 3 replications of each herb species. Mean separation within species not among species. Means connected with the same letter are not significantly different with Tukey's significance test at $p<0.05$. Abbreviations and symbols: ORAC, oxygen radical absorbance capacity; TE, Trolox equivalents; FW, fresh weight; Se, selenium. 


\subsection{Future Directions}

The results from this study indicate the potential of Se-biofortified culinary herb microgreens as a functional food. Studies of biofortification of microgreens has been limited in the literature. This study demonstrated that microgreens of scallions, basil, and cilantro can accumulate high levels of Se with additional beneficial effects on other dietary minerals and antioxidants. Future studies should consider the effects of storage and cooking practices on the nutritional profiles of these products. Studies should also determine the biological effects of consumption of biofortified culinary herbs in human studies over short- and long duration. The potential benefits of consuming Se-biofortified plants over Se supplementation alone should also be assessed in human studies. Finally, studies considering consumer acceptability of Sebiofortified microgreens are necessary to evaluate the practical potential of these functional foods. 